\title{
Domingo Faustino Sarmiento oder die Kontraste einer amerikanischen Romantik
}

In diesem von Humboldt evozierten Spannungsfeld von Zivilisation und Barbarei bewegt sich auch der nächste Denker und Schriftsteller, mit dem wir uns beschäftigen wollen: Domingo Faustino Sarmiento. Sie haben diesen Namen noch nie gehört? Nun, Sarmiento ist für die argentinische Literatur das, was Goethe für die deutsche darstellt: Die jeweilige Literatur ist schlicht undenkbar ohne diesen Schriftsteller. Nachdem wir mit Alexander von Humboldt eine Reise auf den amerikanischen Kontinent unternommen haben, wollen wir gleich in der amerikanischen Hemisphäre bleiben und uns mit den weiteren Entwicklungen des Denkens und Schreibens im Zeichen der Romantik beschäftigen. Und wir tun dies nun wieder in der amerikanischen Welt, in den Amerikas, freilich in den Außertropen, ${ }^{1}$ von denen Humboldt stets die seinen Spuren folgenden deutschen Reisemaler fernzuhalten suchte.

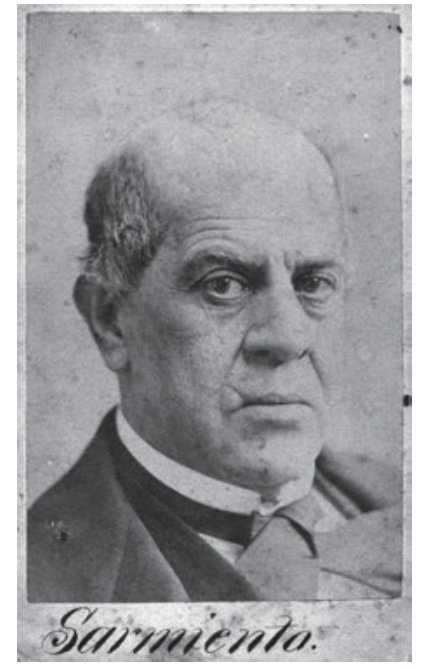

Abb. 53: Domingo Faustino Sarmiento

(San Juan, Argentina, 1811 - Asunción, Paraguay, 1888).

Im Jahre 1845 erschien in der chilenischen Zeitung El Progreso zunächst im Feuilleton der Text eines jungen, seit 1840 in Chile im Exil lebenden Argentiniers, der

1 Vgl. zum Gegensatz zwischen Topen und Außertropen Ette, Ottmar: Diskurse der Tropen Tropen der Diskurse: Transarealer Raum und literarische Bewegungen zwischen den Wendekreisen. In: Hallet, Wolfgang / Neumann, Birgit (Hg.): Raum und Bewegung in der Literatur. Die Literaturwissenschaften und der Spatial Turn. Bielefeld: transcript Verlag 2009, S. 139-165. 
am Beginn einer brillanten Karriere als Journalist, Publizist, und Literat, aber auch als Politiker und Staatsmann stand. Kaum ein argentinischer Intellektueller, Denker und Schriftsteller seiner Zeit dürfte das 19. Jahrhundert so grundlegend geprägt und die Diskussionen selbst im kulturtheoretischen Bereich bis heute so nachhaltig beeinflusst haben wie dieser „Proscrito“, der sich 1840 zum zweiten Mal nach Chile ins Exil vor der Rosas-Diktatur in Argentinien rettete. Jene Bewegung der „Proscritos“ hatten wir ja bereits am Beispiel von Esteban Echeverría kennengelernt und bemerkt, welch ungeheure Dynamik von ihren Köpfen ausging. Mit Sarmiento nähern wir uns nicht dem uruguayischen, sondern dem chilenischen Exil dieser versprengten Argentinier, die von so enormer Bedeutung für die Entwicklung der Literaturen am Río de la Plata waren.

Das autobiographische Element des Exils fehlte keineswegs in jenem Grundlagenwerk, das es jetzt zu besprechen gilt und das erstmals 1845 unter dem Titel Leben des Facundo Quiroga erschien. Wir sollten dieses autobiographische Zeugnis - das nur eines von vielen in einem Band ist, der vorgibt, die Biographie eines gänzlich anderen zu sein, eben Facundo Quirogas - als erstes zur Kenntnis nehmen:

Gegen Ende des Jahres 1840 verließ ich mein Vaterland, gegen meinen Willen verbannt und entstellt, voller Stiche, Hiebe und Schläge, die ich am Vortage während einer jener blutigen Bacchanalien einer mordlustigen Soldateska der Mazorca empfangen hatte. Als ich an den Bädern von Zonda vorbeikam, schrieb ich unter die Insignien des Vaterlandes, die ich in froheren Tagen in einem Saale hinterlassen hatte, mit Kohle diese Worte:

On ne tue point les idées.

Als diese Tat der Regierung mitgeteilt wurde, schickte man eine Kommission mit dem Auftrage aus, diese Hieroglyphe zu dechiffrieren, da man ihr nachsagte, unehrenhafte Stoßseufzer, Beleidigungen und Drohungen zu enthalten. Als man die Übersetzung vernahm, sagten sie: „Na gut! Aber was hat das zu bedeuten? ...“

Es bedeutete schlicht, dass ich nach Chile kam, wo noch die Freiheit strahlte, und mir vornahm, die Strahlen der Aufklärung in der dortigen Presse bis auf die andere Seite der Anden aufleuchten zu lassen. Wer mein Verhalten in Chile kennt, der weiß, dass ich das Versprechen meines Protests erfüllte. ${ }^{2}$

In dieser Eingangsszene von Sarmientos Hauptwerk lassen sich bereits viele jener textuellen Elemente finden und identifizieren, die im weiteren Verlauf seines Facundo weiterentwickelt, pointiert zusammengefasst oder auch geschichtsphilosophisch begründet und verankert werden. Zunächst einmal gilt es aber festzuhalten, dass das Ich - nennen wir es in der Folge unserer Analyse nicht

2 Sarmiento, Domingo Faustino: Facundo o Civilización y Barbarie. Mexico, D.F.: SEP/UNAM 1982, S. 326. 
„Sarmiento“, wie dies bislang in der Forschung oft geschah, sondern einfach den Ich-Erzähler - eine Position einnimmt, welche eine Außerhalbbefindlichkeit gegenüber dem Ort des Geschehens und damit dem argentinischen Vaterlande zum Ausdruck bringt.

Diese von Beginn an schmerzhafte Außerhalbbefindlichkeit steht für Verbannung und Exil - und Facundo ist in der Tat ein Zeugnis jener (innerlateinamerikanischen) Exilliteratur, die schon kurz nach der „Independencia“ im Entstehen begriffen war und bis heute in verschiedenen Schüben und verschiedenen politischen Richtungen, im Grunde aber niemals sehr lange unterbrochen fortdauert. Für nahezu jedes Jahrzehnt - und auch das unsrige macht keine Ausnahme - lassen sich lateinamerikanische Länder aufzählen, die ihre Bürger ins Exil treiben. Facundo ist also ein Stück Exilliteratur: Es ist eine Art vertriebene, besser noch ausgetriebene Literatur. Denn sowohl die Literaten als auch ihre Literatur - nach obigem Zitat offenkundig eine Ideenliteratur - sind des Landes verwiesen und erreichen ihre Leserschaft nicht mehr. Die Exteriorität ist zugleich eine Exterritorialität.

Am Ort des Geschehens, am Ort der Vertreibung kann nur noch eine Spur dieser Vertreibung hinterlassen werden. Das Schreiben an die Wand ist hier ein Beispiel für jene verortete Literatur, die wir anhand von Gedichten bereits in Fernández de Lizardis El Periquillo Sarniento hatten beobachten können. Die Schrift an der Wand, deren Schriftzüge dem Menetekel gleich erst von Schriftgelehrten gedeutet werden müssen, schwebt - analog zum alttestamentarischen Vorbild drohend über der Gewalt des Herrschers, dessen Ignoranz sich in der Ignoranz seiner Schergen zeigt. Ein erstes Gegensatzpaar zeichnet sich bereits in diesen ersten Zeilen ab: Intelligenz gegen Ignoranz.

Das „Writing on the Wall“ ist keineswegs zufällig in französischer Sprache abgefasst. Die Leserschaft, die dieses Zitat als Motto von Hippolyte Fortoul unmittelbar vorher, zu Beginn des Buches, präsentiert bekam, soll es offenkundig mit einer französischsprachigen europäischen Zivilisation verbinden, deren Spur es ebenfalls ist. Denn über allem strahlen die Lichter der Aufklärung („las luces“), für die am Río de la Plata mit Vorliebe die Lichter des französischen „Siècle des Lumières“ stehen. Die Unfähigkeit, diesen Satz zu lesen und zu deuten, weist darauf hin, dass auch die französische Literatur und Ideengeschichte aus jenem Reich, aus jenem Vaterlande vertrieben ist, welches der Ich-Erzähler soeben verließ.

All dies zeigt zugleich, dass sich das eigene Schreiben des Ich auf diese Tradition beruft, indem es ein Zitat aus französischer Feder nach Argentinien, nach Amerika verpflanzt und transplantiert. ${ }^{3}$ Damit ist implizit ein Überset-

3 Vgl. zur Wichtigkeit dieser Metaphorik in Lateinamerika Ette, Ottmar: Transatlantische Transplantationen: Von Pfropfung und „mestizaje“ zum transarchipelischen Zusammenleben in den 
zungsprozess notwendig, der auch in der Tat durch eine Übersetzung des Mottos dokumentiert wird: „A los hombres se les degüella; a las ideas, no.“ In dieser transplantierenden Übersetzung ist das Töten sozusagen interkulturell nach Argentinien übersetzt und erscheint als ein „degollar“, ein Halsabschneiden mit dem Messer, ein Massakrieren, das in der Literatur der Proscritos - aber nicht nur in der Literatur - zum Stigma der Barbarei der Rosas-Diktatur geworden war. Domingo Faustino Sarmiento kann hier an eine lange Tradition anknüpfen, aus der wir bereits Esteban Echeverría kennengelernt hatten.

Aus dieser Perspektive weist die schwarze Schrift an der Wand in eine doppelte Richtung: zum einen explizit nach Chile, wohin sich der Erzähler geflüchtet hat, zum anderen nach Europa und Frankreich, woher er sein Zitat bezog. Die Spur ist daher eine doppelte und die verortete Literatur ist gleichsam nach Osten wie nach Westen ex-zentrisch und extraterritorial. Die Außerhalbbefindlichkeit des Textes ist Grundlage seiner Konstituierung, seiner gesamten Konstruktion. Sie verweist auf das Exil wie auf das Schreiben nicht nur außerhalb Argentiniens, sondern auch außerhalb Europas. Das Faszinierende an Sarmientos Text besteht darin, dass er sich mit beiden ,Exilierungen“ höchst kreativ auseinandersetzt und die Frage der transatlantischen Transplantation immer wieder zum Thema macht.

Ein weiteres wichtiges Element tritt hinzu: Das Ich hat aus der exterritorialen Position in Chile heraus die Möglichkeit erkannt, die Strahlen der Freiheit, die „rayos de las luces“, mithin das Licht der Aufklärung zurückzustrahlen und zu verbreiten. Dies bedeutet nicht nur, dass das Argentinien unter der Rosas-Diktatur mit der Finsternis der Tyrannei und Barbarei implizit konnotiert wird, sondern dass die Möglichkeit der Aufklärung von außen her durchführbar ist und auf Erfolg hoffen darf. Ist die Pressefreiheit in Argentinien auch außer Kraft gesetzt, so ist es doch möglich, über die Presse Chiles zu agitieren und der Diktatur des Juan Manuel de Rosas Schaden zuzufügen: Ideen lassen sich nicht ermorden!

Wenige Monate vor Erscheinen des Facundo war ein Gesandter von Rosas 1845 nach Santiago de Chile gekommen, um unter anderem die Überstellung von Domingo Faustino Sarmiento nach Argentinien zu fordern. Sein Facundo ist die Antwort auf diesen Versuch, jegliche Opposition zum Schweigen zu bringen, aus dem klaren Bewusstsein, mit der Feder aus dem Ausland gegen die Gewaltherrschaft im eigenen Land wirkungsvoll ankämpfen und allen Mordversuchen trotzen zu können. Facundo ist zentraler Bestandteil eines politischen Projekts,

Amerikas. In (ders., / Wirth, Uwe, Hg.): Kulturwissenschaftliche Konzepte der Transplantation. Unter Mitarbeit von Carolin Haupt. Berlin - Boston: Walter de Gruyter 2019, S. 29-65; der gesamte Sammelband enthält eine schöne theoretische Einführung von Uwe Wirth sowie Beispiele von beiden Seiten des Atlantik. 
eines kulturellen und ideengeschichtlichen Vorhabens, darüber hinaus aber auch ein bewegliches Raumprojekt, das die Exteriorität des eigenen Schreibens wieder zu überwinden sucht. Die Strahlen der Aufklärung, die über die Anden nach Argentinien leuchten, nehmen den späteren Weg des Ich-Erzählers vorweg, der mit seinem baldigen Rückweg ins Vaterland die Flucht- und Exilsituation überwinden will und die ausgetriebene Literatur wieder an ihren angestammten Ort zurückführen wird. Denn die Proscritos sollten die in Argentinien künftig Regierenden werden: Sie schrieben die Geschichte und Literatur ihres Landes mit einer erstaunlichen Homogenität, welche sich selbst in ihrer Wortwahl zeigt.

Bleiben wir noch für einen Augenblick bei der Einleitung, die Sarmiento seinem Text in der Ausgabe von 1845 voranstellte! Dort nämlich findet sich die nicht unpathetische Anrufung des Gegenstandes, den der Autor behandeln möchte, den in den Bürgerkriegswirren Argentiniens überaus einflussreichen und im Landesinneren machtvoll herrschenden Caudillo Facundo Quiroga:

Du schrecklicher Schatten, Facundo, ich rufe Dich auf, damit Du den blutigen Staub, der Deine Asche bedeckt, abschüttelst und Dich erhebst, damit du uns das geheime Leben und die inneren Konvulsionen erklärst, welche die Eingeweide eines edlen Volkes zerreißen! Du besitzt das Geheimnis: Decke es uns auf! Zehn Jahre noch nach Deinem tragischen Tode sagten der Mensch der Städte und der Gaucho der argentinischen Ebenen beim Einschlagen unterschiedlicher Wege durch menschenleere Gebiete: „Nein; er ist nicht tot! Er lebt noch immer! Er wird kommen!" Gewiss! Facundo ist nicht tot; in den Traditionen des Volkes, in der Politik und den Revolutionen Argentiniens ist er lebendig; in Rosas, seinem Erben, seiner Ergänzung; seine Seele ist in diese andere, vollendetere, vervollkommnete Form übergegangen, und was bei ihm bloßer Instinkt, Initiation, Tendenz war, verwandelte sich bei Rosas in System, in Wirkung und Endzweck. Die ländliche, koloniale und barbarische Natur verwandelte sich in dieser Metamorphose in Kunst, in System und reguläre Politik, fähig dazu, sich vor dem Antlitz der Welt als Seinsweise eines Volkes zu präsentieren, das sich in einem Manne verkörpert, welcher die Züge eines Genies anzunehmen strebte, das die Ereignisse, die Menschen und die Dinge beherrscht. Facundo war provinzlerisch, barbarisch, mutig, kühn und ward ersetzt durch Rosas, den Sohn des gebildeten Buenos Aires, ohne selbst gebildet zu sein [...]. ${ }^{4}$

Dies ist einer der berühmtesten Anfänge eines literarischen Meisterwerks in Lateinamerika. Denn in diesen wenigen Zeilen hat Domingo Faustino Sarmiento meisterhaft die Konzeption seines Hauptwerks angelegt in einer gewaltigen Sprache, die der Gewalt der von ihm dargestellten Szenen in nichts nachsteht. Die trotzige Anrufung des schon ein ganzes Jahrzehnt lang toten Caudillo, der laute Ruf ins Totenreich also gilt einer Gestalt, die im Besitz eines Rätsels und seiner

4 Sarmiento, Domingo Faustino: Facundo, S. 327. 
Lösung ist. Das Rätsel des argentinischen Volks erscheint dann als lösbar, wenn man Facundo als Schlüssel zu einer wahrlich verzwickten Geschichte ansieht; einer Geschichte politischer Verführungen, so meine ich, die in vielerlei Hinsicht auch heute noch immer nicht zu Ende ist.

Dem gesamten polymorphen, vielgestaltigen Text liegt folglich eine Rätselstruktur zugrunde, die den Spannungsbogen von diesen ersten Zeilen der Einleitung her bis zum Ende des Bandes spannt. Facundo besitzt das Geheimnis, doch allein der Ich-Erzähler kann ihn zum Sprechen bringen. Hierin liegt die Aufgabe dieses erzählenden Ich, das gerade aus der räumlichen Entfernung des Exils wie der zeitlichen Entfernung zum toten Warlord jene Konzeptionen entwickeln will, die Licht in die Finsternis zu bringen versprechen. Denn ohne eine genaue Kenntnis dieser Geschichte, so der Erzähler, kann Argentinien sein Rätsel nicht lösen und sich aus seiner eigenen Geschichte befreien. Aber hat Argentinien dies jemals geschafft? Hat es in Perón, in Evita, in Maradona nicht immer die Heilsbringer gesehen? Es gibt Völker - und ich nehme das deutsche nicht aus -, die in ihrer Geschichte immer wieder gegen ihre eigene Geschichte ankämpfen müssen.

Dabei ist Facundo keineswegs tot: Er lebt in der Tat fort in den Legenden und Erzählungen des Volkes, in jenen „tradiciones populares“, in denen der ,Held“ nach seinem ,tragischen Tode‘ fortlebt. Während sich Esteban Echeverrías Gedicht auf diese volkskulturellen Traditionen hin am Ende öffnet, geht Sarmiento schon zu Beginn auf sie ein, wobei sie ihm als Anknüpfungspunkt seines für die argentinische Geschichte und Literatur so wichtigen Bandes dienen. Hieran lässt sich die spezifische Sensibilität der Romantiker - und auch Domingo Faustino Sarmiento zählt zu ihnen - für die „tradiciones populares“ erkennen. Es sind bei den Romantikern in Amerika nicht allein die europäischen Märchen, Legenden oder Sagen, sondern auch eigene amerikanische Formen von „Leyendas“ und „Tradiciones“, auf denen die literarische Bearbeitung - also die Hochkultur im Sinne unseres ersten Pols - aufbaut und aus denen sich diese romantische Literatur in den Amerikas speist.

Die Biographie eines Mannes und Caudillos - eben Facundo - ist für Sarmiento kein Selbstzweck; sie soll vielmehr die Geschichte eines ganzen Volkes erhellen. Sie ist in Ermangelung einer eigenen argentinischen Geschichtsschreibung auf die politischen Zusammenhänge gerichtet, welche die Geschicke des Landes bestimmten und bestimmen. In diesem größeren historisch-kulturellen Zusammenhang ist Facundo nur eine Gestalt, hinter der sich eine andere verbirgt: Hinter dem Caudillo der argentinischen ,Llanos‘, der argentinischen Pampa, verbirgt sich der Diktator, der in der Stadt Buenos Aires Einzug gehalten und seine Diktatur errichtet hat. Im Aufstieg eines einzelnen Warlords lässt sich der systematische Aufstieg der Rosas-Diktatur im ganzen Land studieren. Zwi- 
schen Facundo und Rosas besteht auf den ersten Blick ein synekdochisches Verhältnis.

Zugleich liegt dem Text eine grundlegende Metonymie, eine Verschiebung zu Grunde: Wenn von Facundo die Rede ist, ist stets auch Rosas mitgemeint. Eine politische und historische Entwicklung hat stattgefunden, welche in der Struktur der argentinischen Gesellschaft selbst angelegt ist: Die Instinkte Facundos sind zum kühlen Kalkül von Rosas geworden, aus der planlosen Gewaltherrschaft ist ein System geplanter Unterdrückung und Ausplünderung geworden. So ist es im Grunde Juan Manuel de Rosas, dem die kraftvolle, gewaltige Sprache dieses großen argentinischen Schriftstellers gilt und gewidmet ist.

Die Beziehung zwischen Facundo Quiroga und Juan Manuel de Rosas ist darüber hinaus historisch gesehen jene des Übergangs zwischen der Kolonialzeit unter spanischer Herrschaft und der politisch unabhängigen argentinischen Republik - allerdings nicht im Sinne eines dialektischen Übergangs, sondern eher im Sinne eines Fortlebens des Kolonialen in der Independencia und den neugeschaffenen politischen Strukturen. Man darf sich den Beginn der argentinischen Republik nicht als strahlenden Neuanfang im Zeichen der Unabhängigkeit vorstellen, sondern als blutigen, von inneren Kämpfen zerrissenen Nationenbildungsprozess, der lange Jahrzehnte gewalttätiger Auseinandersetzungen beinhaltete. ${ }^{5}$ Das koloniale Erbe, so darf man die Passage aus Sarmientos Facundo sehr wohl deuten, lebt in der Gegenwart, lebt in der Rosas-Diktatur fort und ist keineswegs ausgerottet. Wir haben es also deutlich mit einer postkolonialen Problematik zu tun - wohlgemerkt nicht in der zweiten Hälfte des 20., sondern im entstehenden Lateinamerika der ersten Hälfte des 19. Jahrhunderts.

In den an seine Leserschaft gerichteten, den Band begleitenden Erläuterungen betont Domingo Faustino Sarmiento, dass er das Werk zwar in Eile geschrieben habe, dass die dargestellten Gegenstände aber anhand von Dokumenten nachprüfbar seien. Einmal mehr übernimmt die Literatur Funktionen, die sie in Ermangelung einer Geschichtswissenschaft ausüben muss. Damit wird - geradezu selbstverständlich wirkt - Abbildanspruch, ja fast dokumentenhafte Treue gegenüber dem Gegenstand behauptet. Ist Facundo daher nicht allein Biographie eines Caudillo, sondern mehr noch ein Geschichtswerk?

Summieren wir einige der bislang berührten Punkte, so ist Sarmientos Facundo zweifellos eine Biographie des Titelhelden, besitzt aber auch autobiographische Elemente, die auf den ins Exil geflüchteten Autor selbst verweisen. Es handelt sich zudem um eine mit literarischen Mitteln durchgeführte Auf-

5 Vgl. zur Geschichte Argentiniens u.a. Bodemer, Klaus / Oagni, Andrea / Waldmann, Peter (Hg.): Argentinien heute. Politik - Wirtschaft - Kultur. Frankfurt am Main: Vervuert 2002. 
erweckung eines Toten aus dem Jenseits und eine nur so, auf detaillierte Weise zu entwirrende Rätselstruktur. Gleichzeitig geht es um einen Text mit fast dokumentarischem Anspruch, der mimetisch bestimmte Funktionen einer historiographischen Darstellung erfüllt. Noch in den beigefügten Anmerkungen wird auf einen späteren Zeitpunkt verwiesen, zu dem dieses Werk in einen neuen Plan umgeschmolzen werden solle, innerhalb dessen die zahlreichen Digressionen und Abschweifungen verschwinden sollten und offizielle, dereinst zugängliche Dokumente eingeblendet würden.

Noch aber sei der Zeitpunkt - so der argentinische Verfasser aus dem Exil nicht reif für ein solches geschichtsphilosophisch und realgeschichtlich untermauertes Werk; und noch sei die Rosas-Diktatur zu nahe, zu präsent, als dass man sie aus der distanzierten Beobachterperspektive des Historikers betrachten könnte. In der Tat: Sarmiento selbst konnte sich auf eine solche nicht zurückziehen, sondern war vielmehr - wie wir schon in der Analyse des Auftaktzitats sahen - direkt betroffen und nahm eine militante Teilnehmerposition ein, welche diesen Text zu einer Waffe im Kampf gegen die Diktatur in Argentinien machte. Die Rosas-Diktatur täuschte sich nicht, als sie der chilenischen Regierung ihr Auslieferungsgesuch unterbreitete.

In der Einleitung zum Facundo wird freilich darauf verwiesen, dass all diese Voraussetzungen Elemente für eine ,neue Welt‘ darstellten. Auch in diesem literarischen Werk wird letztere also nicht als Erbe der Vergangenheit, sondern als in die Zukunft projizierte, sich in ihren Umrissen noch nicht klar abzeichnende und an keinem Modell, keinem Vorbild orientierte Welt verstanden; ein generationelles Epochengefühl, das wir bereits bei Simón Bolivar auf dem amerikanischen Kontinent beobachten konnten. Die Zukunft ist radikal offen: Es gibt keine historischen Vorbilder, die Geschichte ist nicht länger Magistra vitae! ${ }^{6}$ Alles muss von den Menschen selbst völlig neu gestaltet werden; und so überrascht es auch nicht, dass es wenig später heißt, der argentinischen Republik habe ein Alexis de Tocqueville gefehlt, hatte der französische Essayist mit seiner 1831 unternommenen Reise doch gerade versucht, die Zukunft der Demokratie in Frankreich dadurch aufzuhellen, dass er ihre Gegenwart in den Vereinigten Staaten untersuchte. Wenn es auch keine Vorbilder für die politische Entwicklung gibt, so geht der Blick Sarmientos doch immer wieder nach Europa, mit dessen Schriftstellern sich ein fein gesponnenes intertextuelles Netzwerk transatlantischen Zuschnitts ergibt.

6 Vgl hierzu Koselleck, Reinhart: Historia Magistra Vitae. Über die Auflösung des Topos im Horizont neuzeitlich bewegter Geschichte. In (ders.): Vergangene Zukunft. Zur Semantik geschichtlicher Zeiten. Frankfurt am Main: Suhrkamp 21984, S. 38-66. 
Doch nicht alle Länder Europas zählen zu diesen Bezügen: Spanien, so viel ist sicher, kann das Vorbild nicht mehr sein! Der bereits betonte geokulturelle Dominantenwechsel, der sich noch zu Kolonialzeiten im 18. Jahrhundert ereignete, hat die politischen, sozialen und kulturellen Weichen grundlegend anders gestellt. Die alte Kolonialmacht Spanien verkörpert die Vergangenheit, ist eher das, wovon man sich auf dem amerikanischen Kontinent abheben möchte, was man endgültig abstreifen will: Spanien selbst ist marginal geworden, ja situiert sich in einem Raum, der kaum noch Europa zuzurechnen ist. Die bereits erwähnte Grenzziehung der französischen Aufklärung hat ihre Wirkung getan und Spanien für lange Zeit ins zweite Glied rücken lassen: Erinnern wir uns daran, dass wir bei Fray Servando Teresa de Mier mehrfach auf den bösartigen Spruch gestoßen waren, dass Europa an den Pyrenäen aufhöre und Spanien bereits zu Afrika zähle! In den verschiedensten Areas des in Entstehung begriffenen Lateinamerika ist diese Überzeugung fest verankert. Bei Domingo Faustino Sarmiento liest sich das aus geschichtsphilosophischer Sicht wie folgt:

So konnte das Problem Spaniens ein wenig klarer werden, jenes Nachzüglers Europas, der hineingeworfen ist zwischen Mittelmeer und Ozean, zwischen Mittelalter und 19. Jahrhundert, mit dem gebildeten Europa über einen weiten Isthmus verbunden und vom barbarischen Afrika nur durch eine schmale Meerenge getrennt, balancierend zwischen zwei einander entgegengesetzten Kräften, und es erhebt sich einmal auf der Waage auf der Seite der freien Völker, ein andermal auf jener mit despotischer Herrschaft; bald ist es gottlos und bald fanatisch, einmal despotisch unvorsichtig, seine zerbrochenen Ketten bisweilen verfluchend; ein andermal seine Arme verschränkend und schreiend darum bittend, man möge es unter das Joch nehmen, welches seine Grundbedingung und seine Existenzweise zu sein scheint. ${ }^{7}$

Im Grunde ist in der vor kurzem noch spanisch beherrschten Welt die Meinung über die einstige Kolonialmacht ungeteilt: Spanien ist in der ,Neuen Welt‘ geokulturell abgeschrieben, erscheint als ewig gestriges Land, dessen Personifizierung stets nach neuen Ketten, nach neuer Unterdrückung verlange und diese Tradition im Übrigen an die „España americana“ weitergegeben habe. In der postkolonialen Situation erscheinen allein das Versagen und die Verbrechen des ehemaligen Mutterlandes: Alles zielt darauf ab, das Erbe der einstigen Kolonialmacht möglichst schnell loszuwerden. Auch dieses Spanien in Amerika gilt es zu tilgen, will man - wie es in Facundo beständig wiederholt wird - Anschluss an die europäische Zivilisation finden: Zu dieser aber rechnet man Spanien nicht mehr.

7 Sarmiento, Domingo Faustino: Facundo, S. 330. 
Unübersehbar ist in diesen rhetorisch gut strukturierten und sich an Gegensätzen ausrichtenden Passagen der geokulturelle Dominantenwechsel, der längst nicht mehr eine Forderung, sondern eine Tatsache geworden ist. Und dies war keineswegs nur in der Literatur oder der Philosophie der Fall: Man dachte - so schien es zumindest auf den ersten Blick - wie die Franzosen, Deutschen oder Engländer, man schrieb wie die französischen, englischen oder deutschen Schriftsteller, man orientierte sich gastronomisch mehr und mehr an Frankreich und man kleidete sich ganz selbstverständlich nach der neuesten französischen Mode. Die uns bereits bekannte frühe französische Feministin und Sozialhumanistin Flora Tristan, die 1833 und 1834 einen Teil Chiles und Perus bereiste, stellte zu ihrer großen Freude fest, dass die Kleidung der Amerikanerinnen und Amerikaner längst an französischen Modellen ausgerichtet sei. Zudem bemerkte sie, dass man zum Essen die besten - wenn auch unglaublich teuren - französischen Weine reiche und dass man auch beim Speisen sich längst an den Künsten der französischen Küche orientiere.

Die Geschichte dieser auch kulinarischen Umorientierung ist noch zu schreiben; ungeheuer spannend wird sie sicherlich sein, wenn auch ihr Ergebnis, eine Art zeitweiliges „,afrancesamiento“, wohl feststehen dürfte. Freilich folgten dieser dominanten Ausrichtung an Frankreich seit der zweiten Hälfte des 20. Jahrhunderts zunehmend Bewegungen einer gastronomischen Amerikanisierung - wohlgemerkt nicht im Sinne einer ,Macdonaldisierung', sondern der jeweiligen nationalen Küche. Vergessen wir in diesem Zusammenhang nicht, dass die erste Küche eines Landes, welche von der UNESCO ins Weltkulturerbe aufgenommen wurde, nicht die französische, sondern die mexikanische Küche war!

Gewiss muss man an dieser Stelle eine kategorische Einschränkung machen, denn derlei Usancen gehören selbstverständlich zum Habitus einer ganz bestimmten sozialen Klasse. Bei einer wissenschaftlichen Arbeit ginge es darum, die spezifischen Aneignungsformen dieser im Sinne des französischen Soziologen Pierre Bourdieu verstandenen gesellschaftlichen Distinktion ${ }^{8} \mathrm{zu}$ untersuchen, um herauszubekommen, wie französische Vorbilder und Modelle ,amerikanisiert ${ }^{*}$ und damit ,heimisch' gemacht wurden. Man dürfte auf keinen Fall dabei vergessen, dass die besten französischen Weine natürlich nur einer ganz bestimmten Schicht gereicht wurden: der reichen kreolischen Oberschicht, die spätestens jetzt, zu Beginn des 19. Jahrhunderts, damit begann, ihre hoffnungsvollen Söhne nach London, vor allem aber nach Paris in die „ville-lumière“ zu schicken.

8 Vgl. hierzu die deutsche Übersetzung von La Distinction in Bourdieu, Pierre: Die feinen Unterschiede. Kritik der gesellschaftlichen Urteilskraft. Frankfurt am Main: Suhrkamp 1982. 
Das von Domingo Faustino Sarmiento in seinem Facundo entworfene Bild ist durchaus differenziert: Noch in der „Einführung“ wird die Weitsicht des französischen Historikers und Geschichtsphilosophen François Guizot in Hinblick auf die europäische Geschichte gelobt, dabei aber die Begrenztheit seines Blickes beklagt, sobald es um Amerika gehe. An dieser Stelle wird deutlich der amerikanische Blick auf die amerikanische Welt gefordert, so wie es schon als unangebracht und irreführend erschienen war, einen Simón Bolívar mit europäischen Augen als europäischen General zu sehen. In diesem Zusammenhang deutet sich bereits eine Legitimation des eigenen Standpunkts an, eines amerikanischen Standpunkts nämlich und eigener amerikanischer Formen literarischer Darstellung - eine Forderung, die hier noch nicht explizit erhoben wird, auf die Sarmientos Facundo selbst in seiner literarischen Form aber die überzeugendste Antwort darstellt. Denn Sarmiento verlangte einen argentinischen, einen amerikanischen Weg des Fortschritts, ${ }^{9}$ welcher auch die literarische Formensprache in den Amerikas betraf.

Das Thema des Fortschritts erscheint bereits in der Einleitung, welche die Grundrichtung des gesamten Textes vorgibt: Der „Progreso“ wird zum Grundgesetz sowie Motor der Menschheit und ihrer Entwicklung. Die Flüsse, so heißt es, dürfe man nicht der Barbarei und den „aves acuáticas“, den Wasservögeln überlassen. Gerade die Flüsse werden immer wieder von Sarmiento als Achsen für eine künftige Entwicklung ins Feld geführt, nicht nur, um die unitarische geopolitische Struktur des Landes zu belegen und die Sonderrolle von Buenos Aires am La-Plata-Trichter zu legitimieren. Sarmiento leitet aus der naturräumlichen Anlage Argentiniens eine zentralisierte Regierungsstruktur ab und bedient sich somit geodeterministischer Argumentationsschemata, welche selbstverständlich gegen die Föderalisten und die Rosas-Diktatur gerichtet sind. Im ersten Kapitel prophezeit er Buenos Aires, dereinst die gigantischste Stadt beider Amerikas zu sein und sich aus der „gran aldea“ in eine Metropole zu verwandeln, was im Übergang zum 20. Jahrhundert dann tatsächlich als Vorstellung eingelöst wurde. Daneben betont er die künftige Rolle der Flüsse als industrielle Leitlinien auch, um auf ihnen das Bild einer regen Dampfschifffahrt ins bewegte Bild zu setzen. All dies, so sein fortschrittsoptimistisches Wollen, garantiere gesellschaftlichen Wohlstand und eine immense Zukunft für den noch jungen Staat. Er konnte diesbezüglich auf den großen preußischen Amerika-Kenner Alexander von Humboldt verweisen: Denn nicht viel anders hatte Humboldt wenige Jahrzehnte zuvor das amerikanische Mesopotamien des Orinoco- und Amazonasbereichs als künftige

9 Vgl. hierzu Rodríguez Pérsico, Adriana: Un huracán llamado progreso. Utopía y autobiografía en Sarmiento y Alberdi. Washington, D.C.: OEA - OAS 1993. 
Entwicklungsachse des südamerikanischen Halbkontinents herausgestrichen. Und anders als die europäischen Flüsse waren die südamerikanischen auch für Transatlantiksegler schiffbar.

So überrascht es nicht, dass Domingo Faustino Sarmiento ganz wie Esteban Echeverría, der in La Cautiva zunächst den naturräumlichen Rahmen zum Protagonisten seines Gedichts gemacht hatte, im ersten Teil seines Facundo der naturräumlichen Ausstattung und Struktur sein Hauptaugenmerk schenkt. Damit wird zunächst das entwickelt, was im Buch selbst als das „Theater der Ereignisse“ bezeichnet wird, um in einem zweiten Schritt - eben dem zweiten Teil seines Werks - dann die Titelgestalt darin zu platzieren und mit den bereitgestellten Elementen interagieren zu lassen. Auch wenn Sarmientos Facundo in aller Eile geschrieben wurde: Sein großer Versuch über die argentinische Identitätskonstruktion besitzt eine auf den ersten Blick klare und stringente Grundstruktur, mit der wir uns nun näher auseinandersetzen wollen.

Die unermessliche Weite ist - wie wäre es auch anders zu erwarten - das charakteristische Merkmal Argentiniens; das kennen wir schon aus Echeverrías La Cautiva. Doch diese Weite ist zugleich Argentiniens Problem, ist das Land doch von allen Seiten vom „desierto“ umgeben, ist fast umzingelt von menschenleeren Gebieten. Was unter den herrschenden Kreolen, aber auch unter den kreolischen Exilierten als ,menschenleer bezeichnet wurde, wissen wir schon. Denn im Norden und Süden werde das Land von den „salvajes“ bedroht, als Menschen nicht zählende Wilde, die bei Vollmond Überfälle nicht nur auf Viehherden, sondern auch auf die „indefensas poblaciones“ verübten, die Reisenden bedrohten sowie wehrlose Frauen und Kinder verschleppten. Der große Augsburger Maler Johann Moritz Rugendas hat derartige Überfälle, die sogenannten „Malones“, in zahlreichen Skizzen und Ölgemälden festgehalten.

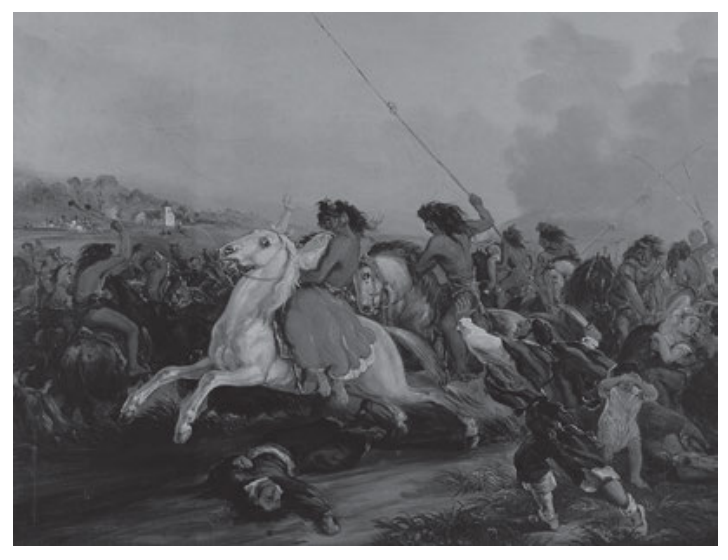

Abb. 54: „El rapto (El Malón)“, Öl auf Leinwand von Johann Moritz Rugendas, circa 1845. 
Deutlich klingt in solchen Passagen Echeverrías Thema der Cautiva an. Der gewaltsame Tod sei, so der Erzähler Sarmientos, fast zu einer Normalität im Leben, aber auch im stoischen Charakter der Argentinier geworden. Der Tod und ein gewaltvolles Ende seien daher nichts Außergewöhnliches für Menschen, die ihn zu empfangen, aber auch zu geben gewohnt sind. Der Gaucho verachte aber nicht nur den Tod, sondern auch die Flüsse, die doch die wichtigste Gabe der Vorsehung für eine Nation seien. Und nicht umsonst sind es gerade in der ersten Hälfte des 19. Jahrhunderts europäische Reisende, die sich entlang der argentinischen Flüsse einen Weg in die unbekannten Weiten des Kontinents zu bahnen versuchen; Unternehmungen, von denen Sarmiento ohne Zweifel wusste und die er teilweise auch anführte.

Die Pampa hingegen ist für Sarmientos Erzähler jener weite Raum, der den zivilisatorischen Impuls nicht oder zumindest doch in nur sehr abgeschwächter Form weiterzugeben in der Lage sei. Das Landesinnere sei vielmehr geprägt von einer deutlich asiatischen Färbung; ein Thema, das im weiteren Verlauf des Buches immer wieder anklingt und die Weiten Amerikas mit den asiatischen Weiten, die Gauchos mit den asiatischen Reitervölkern in Beziehung setzt. Dies erlaubt auch politische Parallelen, werden doch so Beziehungen zur (schon damals) sprichwörtlichen asiatischen Despotie gezogen. Diese Abwertung des Ostens gehört zum Orientalismus, den Sarmiento aus den europäischen Literaturen seiner Zeit entnahm..$^{10}$ Dass die Terme ,Orientalismus' und ,orientalistisch“ angesichts der Kugelform der Erde nur aus Europa heraus Sinn machen, erübrigt sich im Grunde zu erwähnen. Dass später ein von den USA auf Lateinamerika bezogener Latinamericanism als Begriff geschaffen wurde, ${ }^{11}$ würde uns in der Diskussion dieser Vorlesung allerdings zu weit führen.

Als Gegenbild führt der Erzähler des Facundo die schottischen und deutschen Einwandererdörfer ins Feld, in denen - ich komme darauf ein wenig später noch einmal zurück - alles geordnet zugehe, die Kühe beständig gemolken sowie Milch und Käse produziert würden. Mit anderen Worten: Der Faulheit der Indianer, der Spanier und Mestizen, der Zambos und Mulatten wird der Fleiß und die Tüchtigkeit nord- und mitteleuropäischer Einwanderer gegenübergestellt, die - so zeigt die Beschreibung - ihre europäischen Erfahrungen in Amerika einbringen und das ganze Land voranbringen können: Diese Einwanderer sind hochwillkommen!

10 Vgl. hierzu das Standardwerk von Said, Edward W.: Orientalism. New York: Vintage Books 1979.

11 Vgl. hierzu Santí, Enrico Mario: Latinamericanism and Restitution. In: Latin American Literary Review (Pittsburgh) XX, 40 (July - December 1992), S. 88-96. 
Im Gegensatz hierzu stehen die Ortschaften des „Interior“ für die Barbarei ein: Die Bevölkerung ist über weite Flächen disseminiert, Ansatzpunkte für zivilisatorische Einrichtungen fehlen. Davon setzt sich umso deutlicher die Stadt als Gegenbild ab: Sie ist Zentrum der Zivilisation und beherbergt in ihrer regelmäßigen Anlage alles, was die ,pueblos cultos“, die kultivierten Völker ausmache. Alle Attribute europäischer Zivilisation, von den Schulen bis zum Frack, sind an die Städte, an die Stadtzentren gebunden. Die Gegensätze zwischen Stadt und Land erscheinen dem Beobachter als so stark, dass er glauben könnte, es handle sich um zwei verschiedene Völker: Der Zivilisation der Stadt steht die Barbarei des Landes nahezu unvermittelt gegenüber.

Diese Barbarei freilich hat durchaus ihre Größe. Im Jahre 1838 will der IchErzähler an einer Szenerie beteiligt gewesen sein, die ihn an die primitiven Zeiten der Welt vor der Institutionalisierung einer Priesterkaste erinnerte. Denn 1838 erlebt er - und dies ist ein weiteres autobiographisches Element - ein gleichsam prähistorisches Gebet, das ihn ob seiner Vollkommenheit zum Weinen gebracht habe, wurde doch dort vom Himmel ergiebiger Regen, Fruchtbarkeit für die Herden und Schutz ihrer Bestände erfleht. Dagegen biete das Christentum heute ein Bild der Korruption, eine Lehre ohne Glauben und Überzeugungskraft.

Die Reise ins Landesinnere ist für den Ich-Erzähler also eine Reise in die Vergangenheit, nicht nur in die Vergangenheit des Ich, sondern der Menschheit insgesamt. Reisen wird hier zur bewegbaren Zeitmaschine, welche die Ungleichzeitigkeit des Gleichzeitigen - Prähistorie, Mittelalter, Moderne leben im selben Land miteinander vereint und in unmittelbarer Nähe zu den Wilden, den „salvajes“ - erlebbar macht. Die Zweiteilung der Reisen nach und in Amerika, die wir in einem eigenen Kapitel anhand von Texten Flora Tristans und Alexis de Tocquevilles untersuchten, bestätigt sich auch hier: Die Reise ins „Interior“ gerät zur Reise in eine sonst kaum mehr zugängliche Vor-Zeit.

Innerhalb dieser Welt der unermesslichen Weiten der Pampa lebt der Gaucho; ein ,Landschaftselement", das sich noch über lange Jahrzehnte bis in die zweite Hälfte des 20. Jahrhunderts hinein - etwa in den Erzählungen und Romanen von João Guimarães Rosa ${ }^{12}$ aus dem brasilianischen Sertão - finden lässt. Seine Erziehung ist ganz auf körperliche Tüchtigkeit und Geschicklichkeit hin ausgerichtet, sein Leben bewegt sich im Rhythmus der Herden, für die er Sorge tragen muss. Sarmiento liefert hier ein beeindruckendes und das ganze Jahrhundert prägendes Bild des Gaucho, in welchem keineswegs nur die Verachtung alles Barbarischen, sondern auch ein Gutteil Bewunderung des in der Provinz aufgewachsenen „Sanjuanino“ Domingo Faustino Sarmiento mitschwingt.

12 Vgl. Ette, Ottmar: Von den historischen Avantgarden bis nach der Postmoderne, S. 773-810. 
Es wäre daher irreführend - wie dies lange Zeit in Teilen der Forschung geschah -, die von Sarmiento gesetzte Antithese zwischen Zivilisation und Barbarei absolut zu setzen und nicht verstehen $\mathrm{zu}$ wollen, dass es oft das abgewertete autochthone Element ist, das dem Schriftsteller immer wieder die gewaltigsten und literarisch überzeugendsten Darstellungen abnötigt. Diese literarischen Höhepunkte folgen einander, ohne dass der Erzähler dabei vergäße, den jungen Dichter Echeverría und dessen Gedicht La Cautiva zu erwähnen, dem mit guten Gründen eine entscheidende Rolle bei der ästhetischen Erfassung der Weiten Argentiniens völlig zurecht zugeschrieben wird. Sarmientos Vision der Pampa kann auf Echeverrías Ästhetisierung der weiten, ,menschenleeren' Gebiete nicht verzichten.

In seinem Facundo wird Sarmiento explizit: Hätten Echeverrías neoklassizistische Vorgänger der europäischen Literatur nichts hinzugefügt, so habe ersterer doch seinen Blick den ,inmensidades“ und dem „desierto“ zugewandt. Er tat dies nicht anders als Fennymore Cooper, der mit seinem Letzten Mohikaner nicht nur als einziger nordamerikanischer Romancier die Aufmerksamkeit Europas auf sich gezogen habe, sondern Praktiken darstellte, welche auch in der Weite der argentinischen Pampa Anwendung finden würden. Es geht hier um Vorbilder für eine Darstellung dessen, was bislang in den Literaturen noch nicht dargestellt worden war. Und es geht dabei keineswegs ,nur' um eine Ästhetisierung des Landesinneren mit seinen Kordilleren und weiten Ebenen, sondern auch um die Darstellung jener Lebensformen, jener kulturellen Ausdrucksformen, welche sich in diesen Gebieten entwickelten.

Esteban Echeverría und andere argentinische Barden werden von Sarmiento hervorgehoben, doch repräsentierten sie ,nur“ die „poesía culta“. Es gebe aber noch eine andere Poesie als die der Stadt, nämlich jene, welche der Text als „poesía popular“ bezeichnet, die des Gaucho. Hier haben wir es mit einer Aufwertung zu tun, die ohne die Vorgeschichte der europäischen, speziell auch der deutschen Romantik gar nicht gedacht und zum Ausdruck gebracht werden kann. Denn fortan werden populäre, also volkstümliche, beim Volk verhaftete kulturelle Formen interessant. Der Erzähler hebt bewundernd die musikalischen Fähigkeiten der Mestizen, vor allem aber der Gauchos und ihrer volkskulturellen Traditionen hervor: Dies sind neue Töne, wie sie so noch niemals zuvor in den Literaturen des spanischen Amerika hörbar wurden. All dies ist insoweit bedeutend, als damit der volkskulturelle Pol nicht mehr nur verwendet, sondern auch gewiss in engen Grenzen - aufgewertet und als eigene kulturelle Äußerungsform verstanden wird. Dies betrifft gerade auch die kleineren musikalischen Formen, die von der Hochkultur zuvor verachtet worden waren. Die Gitarre als spanisches Element, ja der spanische „Majo“ seien noch bis heute überaus lebendig: man könne ihn im „Compadrito“, aber auch im Gaucho auf dem Land erkennen und 
noch immer identifizieren. Das Andalusische sei noch bis heute in durchaus authentischer Form zu vernehmen. Die hochkulturelle Literatur schließt sich in den Amerikas für die kleineren populären Formen auf, so wie in der europäischen Romantik das Interesse an Märchen, Legenden und volkstümlichen, nicht verschriftlichten Erzählungen auf breiter Front erwacht war.

In der Folge werden in Sarmientos Text vier Figuren, im eigentlichen Sinne exemplarische Typen, eingeführt: Rastreador, Baqueano, Gaucho malo und Cantor. Sie bilden Grundtypen, die im zweiten Teil des heterogenen Textgebildes dann gleichsam aus der statischen Deskription in lebendige Bewegung versetzt werden. Die vielleicht außergewöhnlichste Figur ist die des Rastreador, des Fährtenlesers, der größte Achtung im Landesinneren genieße, da er ein Wissen beherrsche, welches für die Landbewohner von direkter Nutzbarkeit und Wichtigkeit ist. Ihm kommt eine fast gottgleiche Funktion zu, wenn er Verbrechern im wörtlichen Sinne auf die Spur kommt und mit dem Finger auf sie zeigt: „Der war es!“ Eine Reihe recht unwahrscheinlich klingender Erfolge des berühmten Fährtensuchers Calíbar dokumentieren die Bewunderung des Ich-Erzählers (und zweifellos Sarmientos) für diesen argentinischen Typus; eine Bewunderung, die er auch dem Baqueano, dem Kenner des Landes und seiner Wege entgegenbringt. Manche Baqueanos hätten es im Übrigen aufgrund ihres Ansehens und ihrer Wichtigkeit zu Generälen, ja zu Staatsmännern gebracht - aber auch zu Diktatoren wie Rosas, der das Weidegras der verschiedenen Vieh-Estancias am unterschiedlichen Geschmack erkennen könne. Dabei fällt einem Alexander von Humboldt ein, der am Orinoco die Indianer darum beneidete, die verschiedenen Bäume anhand des Geschmacks ihrer Borke voneinander unterscheiden zu können. Alexander selbst konnte trotz aller Versuche keine geschmacklichen Unterschiede zwischen den Baumrinden feststellen.

Damit kommen wir schon zum Typus des Gaucho malo, eine fast schon mythische Figur, die in ihrer ganzen Gefährlichkeit und Rücksichtslosigkeit inszeniert wird. Noch im 20. Jahrhundert können wir sie in der brasilianischen Prosa eines João Guimarães Rosa bei der Arbeit bewundern. ${ }^{13}$ Der Gaucho malo ist ein „salvaje de color blanco“, ein Wilder von weißer Hautfarbe, jedoch kein Bandit oder Räuber, was Sarmientos Ich-Erzähler vehement unterstreicht. Der Cantor wiederum wird als Barde, als Vate und Troubadour des Mittelalters präsentiert, den bei seinen Streifzügen durch das Land nichts erschüttere, habe er doch schon alles gesehen. Die Schlussfolgerung aus diesen Überlegungen ist eindeutig:

13 Vgl. hierzu Ette, Ottmar / Soethe, Paulo Astor (Hg.): Guimarães Rosa und Meyer-Clason. Literatur, Demokratie, ZusammenLebenswissen. Berlin - Boston: Walter de Gruyter 2020. 


\begin{abstract}
In der Republik Argentinien sieht man gleichzeitig zwei verschiedene Zivilisationen auf ein und demselben Boden: eine entstehende, die ohne Kenntnis von alledem, was sie über ihrem Kopf hat, die naiven und volkstümlichen Bemühungen des Mittelalters fortführt; und eine andere, die sich nicht darum schert, was sie vor ihren Füssen hat und versucht, die neuesten Ergüsse der europäischen Zivilisation in die Wirklichkeit umzusetzen. Das neunzehnte Jahrhundert und das zwölfte Jahrhundert leben zusammen: das eine in den Städten, das andere auf dem Lande. ${ }^{14}$
\end{abstract}

Die in diesen Ausführungen von Sarmientos Erzählerfigur vorgetragenen kulturtheoretischen und geschichtsphilosophischen Überlegungen sind in mehrfacher Hinsicht bemerkenswert: Sie betreffen zum einen die Kopräsenz kultureller Phänomene und Gegenstände, die verschiedenen Zeitaltern, verschiedenen Jahrhunderten angehören. Man könnte in einem ganz an Ernst Bloch ausgerichteten Sinne von einer Gleichzeitigkeit des Ungleichzeitigen sprechen. Denn über mehrere Jahrhunderte hinweg, so die These des Erzählers, leben zwei Zivilisationen nebeneinander her, ohne sich wirklich zu berühren und miteinander in Kontakt zu stehen. Charakteristisch ist dabei, dass die großen Landflächen um Jahrhunderte in der Zeit gegenüber den Städten zurückhinken, dass weite Teile Amerikas folglich einer Vergangenheit angehören. Das „Interior“ Amerikas erscheint wie ein anderes Mittelalter Europas.

Dies bedeutet, dass im Facundo - und keineswegs nur an dieser Stelle ein Phänomen auftaucht, das in den achtziger und neunziger Jahren zumeist als soziokulturelle Heterogenität oder auch als kulturelle Hybridität bezeichnet wurde. ${ }^{15}$ Verschiedene und mehr noch höchst gegensätzliche kulturelle Welten leben zusammen, ohne dass es notwendigerweise zu einer Homogenisierung kommen müsste. Dies ließe sich zweifellos am besten in die Theoriemetapher des Hybriden, also der kulturellen Hybridität Lateinamerikas fassen. Dabei handelt es sich freilich um eine Hybridität, die Sarmiento anhand einer Chronologie aufzuzeigen versucht, welche allein an der geschichtlichen und kulturellen Entwicklung Europas ausgerichtet ist - so als gäbe es nur einen einzigen, von Europa vorgezeichneten zivilisatorischen Weg.

Nur in diesem hybriden, nicht miteinander vermischten Sinne koexistieren glaubt man der oben zitierten Passage - das zwölfte und das neunzehnte Jahr-

14 Sarmiento, Domingo Faustino: Facundo, S. 40.

15 Vgl. hierzu Cornejo Polar, Antonio: Indigenous and heterogeneous literature: their dual sociocultural status. In: Latin American Perspectives 16 (Spring 1989), S. 12-28; García Canclini, Néstor: Culturas híbridas. Estrategias para entrar y salir de la modernidad. México: Grijalbo 1990; sowie Ette, Ottmar: ¿Heterogeneidad cultural y homogeneidad teórica? Los „nuevos teóricos culturales“ y otros aportes recientes a los estudios sobre la cultura en América Latina. In: Notas (Frankfurt am Main) 7 (1996), S. 2-17. 
hundert miteinander. Zugleich ist die Präsenz der europäischen Moderne überaus gefährlich, scheint sie doch unweigerlich das Mittelalter in Amerika zu gefährden und zu bedrohen. Dabei müssen wir selbstverständlich bedenken, dass es in den Amerikas kein Mittelalter im abendländischen, kulturgeschichtlich europäischen Sinne gab. Damit verbunden ist also eine geschichtsphilosophische und kulturtheoretische Teleologie, der zufolge die damals aktuelle Heterogenität überwunden werden würde und an ihre Stelle eine Homogenität treten müsse, jene Europas, die in ihren neuesten Äußerungsformen in Amerika bereits Präsenz zeigt. Die nationalstaatlich homogenisierenden Aspekte dieser Vorstellung sind ebenso offenkundig wie ihr impliziter Eurozentrismus.

Zum anderen enthält diese Passage aber auch die Anerkennung nicht nur der Zivilisation der (europäischen) Moderne als der einzigen Moderne, sondern auch der Kultur des Gaucho malo, des Rastreador, als Zivilisation. In dieser Passage werden keineswegs Zivilisation und Barbarei einander antithetisch gegenübergestellt, wie dies an anderer Stelle durchaus geschieht, wie es aber vor allem in der Forschung allzu lange und allzu vergröbernd herausgestellt wurde. Fraglos gibt es in Facundo zu dieser Problematik im höchsten Maße widersprüchliche Aussagen. Und doch zeigt sich, dass Sarmiento nicht umhin konnte, der ,mittelalterlichen' Kultur der amerikanischen Troubadoure eine zivilisatorische Adelung zu gewähren; auch wenn es fast so wie die letzte Ölung wirken mag, die man einer untergehenden, todgeweihten Kultur mit auf den Weg ins Jenseits gibt.

Ihre Vitalität steht freilich nicht zur Debatte: Sie ist es ja gerade, die sich unter der Rosas-Diktatur selbst im Raum der Stadt Gehör verschaffte, ja zur politischen und kulturellen Dominanz gelangte. Auch im Facundo fehlen nicht jene Passagen, die sich schon in Echeverrías El Matadero nachweisen lassen und von jener ungeheuren Ausstrahlungskraft und Faszination zeugen, welche die argentinische Kultur der Gauchos, der Sänger und Fährtenleser auf die Intellektuellen der großen Städte ausübte. Dieser enormen Faszination verdanken die dargestellten Typen in Sarmientos Facundo ihre Kraft, ihre Prägnanz, ihre ästhetische Wirkung auf die damalige Leserschaft wie auf die Leserinnen und Leser der zweiten Hälfte des 19. Jahrhunderts - eine Wirkung, die bis heute anzuhalten scheint.

Die große Ausstrahlungskraft der ruralen Kultur auf die städtischen Intellektuellen lässt sich zweifellos in Verbindung bringen mit jener romantischen Sensibilität für vergehende oder vergangene Kulturformen, für die ,Reste“ der Volkskultur oder auch für das Mittelalter, die für die Zeit seit den dreißiger Jahren im Cono Sur epochenspezifisch ist. Das Spezifikum der hispanoamerikanischen Romantik tritt somit deutlicher hervor: Es handelt sich um eine Romantik, die gleichsam vielkulturell ist, auf den Beziehungen zwischen verschiedenen, unterschiedlichen Kulturen aufruht und sich in einer Dezentriertheit gegenüber den Zentren, in einer peripheren Randlage weiß. Eben an dieser Stelle ergibt sich eine 
ganze Reihe von Beziehungen zwischen verschiedenen kulturellen Polen, welche innerhalb der Romantik nur zwischen Peripherie und Peripherie aufgebaut werden konnten.

Zugleich tritt eine ,Orientalisierung‘ des Gaucho hinzu, insoweit sich bei den Gauchos eine ähnliche Verehrung des Sängers, eine ähnliche Liebe für Pferd und Zaumzeug finden wie bei den Arabern. Diese ,Orientalisierung‘ trägt mitunter durchaus positive Züge, wie ein Zitat von Victor Hugo zeigt, das auf die Argentinier übertragen, eigentlich aber auf die Araber gemünzt gewesen war. Domingo Faustino Sarmiento greift in seinem Facundo mehrfach zurück auf die Woge des „orientalisme“, die Frankreich im 19. Jahrhundert erfasst hatte und nicht nur die Romantiker in ihren Bann schlug. Die Arabisierung der Kultur in den weiten amerikanischen Flächen wird freilich in der Folge wesentlich weniger positive Aspekte annehmen und eher die Vorzeichen einer Un-Kultur erhalten, mit Hilfe derer die asiatische Tyrannei der Rosas-Diktatur gebrandmarkt werden soll. Die Vorstellung der genannten vier Grundtypen bietet Sarmiento allerdings eine konstruktive Möglichkeit, diese statischen Elemente in durchaus ambivalenter Weise im weiteren Verlauf der Geschichte in lebhafte Bewegung zu setzen. Denn der Leser - so heißt es im Text - werde, sei die Geschichte erst einmal in Gang gekommen, schon erkennen, welche realen Figuren diesen Typen von Rastreador, Baqueano, Gaucho malo und Cantor entsprächen.

Vor diesem Hintergrund dürfen wir auch auf die literarische Form blicken, die Sarmientos Schreiben sich schuf: keiner klaren Gattung folgend, keiner von der europäischen Tradition sanktionierten Diskursform huldigend, sondern an der spezifisch argentinischen Situation orientiert jene literarische Form kreierend, die den eigenen Bedürfnissen und jenen der Leserschaft wohl am ehesten entsprach. Facundo Quiroga ist laut Sarmiento ein Produkt der amerikanischen Barbarei; aber Sarmientos Facundo selbst, sein Buch also, ist nicht weniger ein Produkt jener Ungezügeltheit, jener alles Klassische, alles Homogene fliehenden Prägungen, die dem Autodidakten Sarmiento seine Stärke, seine Faszinationskraft bis heute vermittelten. Sarmiento ist in dieser Hinsicht wie sein Erzähler die Fortsetzung des von ihm so mit Hassliebe betrachteten Cantor; ja er repräsentiert diese Figur des volkstümlichen Sängers, des argentinischen Barden, mit seiner rauen, nicht europäisch kultivierten Stimme selbst.

Ich möchte damit unsere kurze Untersuchung des ersten von drei Teilen des Facundo abschließen! Es handelt sich dabei um jenen Teil, der die geschichtsphilosophischen, ideologischen, kulturtheoretischen, anthropologischen, charakterologischen und auch autobiographischen Grundlagen für die beiden nachfolgenden Teile bereitstellt, deren erster dem Titelhelden, eben Juan Facundo Quiroga, der Inkarnation des Gaucho malo gewidmet ist. Wir können auf der Grundlage des bereits Analysierten nun schneller voranschreiten, um noch besser zu begreifen, 
wieso Domingo Faustino Sarmientos Facundo so charakteristisch für das argentinische wie lateinamerikanische 19. Jahrhundert mit all seinen intertextuellen und kulturellen Bezügen zu Europa ist.

Sarmientos Hauptwerk ist auch eine Biographie. Und wie es sich für eine Biographie gehört, ist das erste Kapitel des zweiten Teils mit „Kindheit und Jugend“ Facundos überschrieben. Doch wird der Held dieser Biographie keineswegs nach einem stur chronologischen Schema eingeführt, sondern erscheint wahrlich spektakulär auf der Bühne des Geschehens: Denn ein Gaucho rettet sich vor den Verfolgungen der Justiz ins „Desierto“, eine menschenleere, menschenfeindliche Landstrecke zwischen San Juan und San Luis in der Hoffnung, bald von seinen Kumpanen erreicht zu werden, die ihm das für die Flucht notwendige Pferd mitbringen sollen. Bald schon hört man das schreckliche Brüllen eines furchterregenden Tigers, der seit längerem die Gegend unsicher macht und rasch wird aus der Flucht vor der Justiz die wesentlich gefahrvollere Flucht vor dem hungrigen Raubtier.

In höchster Not rettet sich der Gaucho auf einen einzeln stehenden Baum, in dessen schwankender Krone er zwar den Augen des herannahenden Tigers nicht verborgen, wohl aber vor dessen Angriffen vorübergehend geschützt bleibt. Der Tiger blickt den Gaucho mit blutunterlaufenen Augen, mit seiner „mirada sanguinaria“ so intensiv an, dass die faszinierende Anziehungskraft dieses Blickes den Geflüchteten schwächt. Mensch und Tier, Auge in Auge, Tod oder Leben: Hier herrscht allein das Gesetz des Stärkeren. Zum Glück für den Gaucho finden seine Kumpane nicht nur seine Spur und jene des Tigers, sondern auch die beiden selbst vor, noch bevor es zum entscheidenden Zweikampf zwischen Mensch und Raubtier gekommen ist. An dieser Stelle setzt unsere nächste Kostprobe aus Facundo ein, die vielleicht erklären mag, warum das Buch so attraktiv für zeitgenössische wie für spätere Leserschichten ist:

In der Tat hatten seine Freunde die Spur des Tigers gesehen und waren ohne Hoffnung, ihn noch zu retten, in die Richtung gerannt. Das verstreute Zaumzeug enthüllte ihnen den Ort der Szene, und zu ihm hinzueilen, die Lassos zu entrollen, diese über den Tiger zu werfen, der verpackt und verblendet vor Wut war, war das Werk von Sekunden. Das von zwei Lassos niedergestreckte Raubtier konnte den wiederholten Messerstichen nicht mehr entweichen, mit denen ihn aus Rache für seine lange Agonie jener durchbohrte, der das Opfer des Raubtiers hätte sein sollen. „Damals habe ich erfahren, was Angst ist“, sagte General Don Juan Facundo Quiroga, als er einer Gruppe von Offizieren diese Begebenheit erzählte.

So nannten sie ihn den Tiger der Ebenen, und dieser Ehrentitel stand ihm wahrlich nicht schlecht zu Gesicht. ${ }^{16}$

16 Sarmiento, Domingo Faustino: Facundo, S. 74. 
So vermag Domingo Faustino Sarmiento zu schreiben! Der Gaucho malo, der im Übrigen wie Sarmiento selbst aus San Juan kommt, wird gerettet, gleichzeitig erstmals namhaft gemacht und mit seinem Rang genannt: Es ist niemand anderes als Facundo selbst. Aus der Stimme des Erzählers ist kunstvoll die Stimme Facundos geworden, der seinen Offizieren von der Anekdote erzählt. Doch gleich danach übernimmt wieder die Stimme von Sarmientos Erzähler.

Halten wir fest: Aus dem von der Justiz verfolgten Außenseiter ist offiziell ein General geworden, der die Geschicke des Landes prägt! Bereits sein erster Auftritt ist verbunden mit den Semen Feindschaft gegenüber der Zivilisation, Brutalität, Blut, Messer, Kampf auf Leben und Tod, Zustechen ohne jedes Erbarmen. Facundo tötet den Tiger so, wie die Fleischhauer in Echeverrías El Matadero den Stier getötet hatten: in körperlichem Kontakt und mit dem Dolch, dem Messer. Dabei springt das Grausame des Raubtiers über auf die Grausamkeit des Menschen ganz so, wie der Name des Tigers auf Facundo übergeht. Ebenso wie später der Blick Facundos jenem blutrünstigen Blick des Tigers gleichen wird, der sein Leben einst bedrohte, wird er selbst gegenüber seinen Mitmenschen zu jenem Tiger, der blutrünstig immer neue Opfer fordert. Der Spitzname „El Tigre“ passt auf Facundo!

Die Metonymie, jene semantische Verschiebung, die den ersten Auftritt Facundos mit dem Tiger und als Tiger prägt, hat Folgen: Facundo verkörpert den Tiger - auch sein Schädel gleiche dem eines Tigers -, verkörpert die amerikanische, zivilisationsfeindliche Natur und deren Prinzip von Kampf und Gewalt sowie dem Recht des Stärkeren. Die Biographie Facundos wird diese semantische Ebene, diese Isotopie fortführen: Das vermeintliche Opfer wird selbst zum Schlächter, bevor es seinerseits zum Opfer werden wird. Denn Facundo erliegt dereinst einem noch schlimmeren Raubtier derselben Abstammung: Juan Manuel de Rosas, dessen autokratischer Herrschaft vorrangig der dritte Teil des Buches gewidmet ist. Wir sehen: Metonymien wie ständige semantische Verschiebungen bilden eines der literarischen Hauptverfahren in Sarmientos Facundo. Da spielt es keine Rolle, dass die Fauna Argentiniens und Südamerikas keine Tiger kennt, wie die Biologen unter ihnen vielleicht wissen: Der Volksmund hat die Raubtiere so genannt und der Volksmund hat diesen Beinamen auch diesem gewissenlosen Gaucho malo gegeben.

Anhand von Anekdoten werden der Leserschaft der Lebensweg und die charakterliche Entwicklung Facundos sozusagen sozialgenetisch und zugleich repräsentativ für diese Gesellschaft Argentiniens vor Augen geführt. An den Unabhängigkeitskämpfen nahm Facundo teil, ohne freilich deren Ideale - und die Ideale ihrer Generäle - zu teilen. Stets brechen in allen Situationen Facundos Leidenschaften ungezügelt durch: Seine Blicke werden schnell zu Messerstichen. Durch Geschicklichkeit und Schläue, durch eine Vielzahl von Fähigkeiten, die der 
Erzähler keineswegs abstreitet, erreicht Facundo die Achtung, die Anerkennung, ja die Bewunderung und treue Gefolgschaft seiner Leute. Er wird zu jenem Caudillo, zu jenem Warlord, als den man ihn verehrt und fürchtet.

Bald fehlen auch transzendente Attribute nicht: Bisweilen erscheint Facundo als Statue eines zürnenden Jupiters, als Bild eines unnachgiebigen Gottes beim Jüngsten Gericht. Als solcher greift er in die Geschicke der argentinischen Stadt La Rioja ein, die in ihren Grundzügen als Palästina vergleichbares Araberland erscheint, in welchem noch wie im mittelalterlichen Italien die alten Geschlechterkämpfe ausgefochten werden. Sarmiento bleibt sich treu und schildert das europäische Mittelalter im Hinterland von Buenos Aires.

Durch militärische Erfolge, gelungene Mordanschläge und geschicktes Taktieren gelingt es dem aufstrebenden Heerführer, 1835 zum Herrscher über La Rioja und ihre gesamte Region aufzusteigen. Zerstörung und ungebremste Habsucht sind neben der Gewalttätigkeit Merkmale seiner autokratischen Gewaltherrschaft. Insoweit könne man auch nicht davon sprechen, dass Facundo ,regiere‘: Er verwandelt vielmehr in der Folge La Rioja in eine Kriegsmaschinerie für die Durchsetzung seiner eigenen autokratischen Ziele. Zum Kontrast wird Rivadavia angerufen, dessen Präsidentschaft 1826 begann. Während die Caudillos des „Interior“ die Abtrennung vom Ausland verfolgen, gebe es noch immer jenes Argentinien, das Kontakt nach außen suche und mit der Welt verbunden sei, so der Erzähler. Die einen würden nach Föderation, die anderen nach einer Zentralregierung schreien: Die Grundstrukturen eines Zweiparteiensystems, wie es auf dem amerikanischen Kontinent vorherrscht, scheinen gelegt. Das politische Argentinien wird bald in „Federales“ und in „Unitarios“ zerfallen.

So versucht der Erzähler Sarmientos nach eigener Aussage, die geographische und politische Karte der verschiedenen Vorstellungen und Ideen zu entwerfen. Als anschauliche Gegenpole werden dabei die Städte Córdoba und Buenos Aires herangezogen: Wie immer folgt Sarmiento seiner Leidenschaft, in Oppositionen zu denken. Bis 1825 seien jedenfalls diese beiden Städte die vorherrschenden Gegenpole der argentinischen Republik gewesen. Das schöne Córdoba sei das einzige Beispiel mittelalterlicher Stadtarchitektur in Amerika und verkörpere bis ins 19. Jahrhundert den spanischen Geist, von dem Sie übrigens selbst heute noch etwas in der Stadt verspüren können. Aus den „Claustros de Córdoba“ seien nicht weniger als acht Generationen von Doktoren, Theologen, Rechtsgelehrten hervorgegangen. Doch sei die ganze Stadt letztlich nichts anderes als ein einziges „Claustro“; und eines zumal, das nicht um sich herum blicke und etwa das Land in einem realistischen Licht sehe. Natur, Kunst und Geist hätten die Stadt geformt, sie sei gleichsam natürlich zu einer „enclaustrada“ geworden; hier habe es keinen Platz für die revolutionären Ideen eines Rousseau, eines Voltaire, eines Mably gegeben. Mit anderen Worten: In den noch mittelalterlich iberisch geprägten 
Mauern von Córdoba habe der geokulturelle Dominantenwechsel von Spanien zu Frankreich und England nicht stattgefunden.

Dagegen biete Buenos Aires das Bild einer dynamischen, zukunftsorientierten Stadt, deren Karriere fast als unwiderstehlich erscheint. Die Opposition ist stark und verblüfft angesichts einer Stadt, die im Rückblick von der argentinischen Historiographie noch als „la gran aldea“, als das große Dorf bezeichnet wird. Waren, Bücher, Ideen würden im Hafen der Stadt umgeschlagen. Buenos Aires halte sich zunehmend für eine Fortsetzung Europas, insbesondere des französischen Geistes; eine Vorstellung, die im Übrigen auch im 20. Jahrhundert zumindest bis in die sechziger Jahre noch nachzuweisen sein dürfte. Buenos Aires erscheint im Gegensatz zu Córdoba, aber auch zu Bolivars Caracas als eine „ciudad entera de revolucionarios“, als eine Stadt, die hinter den Revolutionären stehe und für die Revolution kämpfe.

Die Kapitale am Río de la Plata ist ein Zentrum der Zivilisation: Enthispanisierung, Europäisierung und Anbindung an fremde Nationen seien nirgends in Amerika so stark wie in Buenos Aires. Buenos Aires, so heißt es hier noch ganz unbedarft, übernahm die Ideen Europas, seien es nun die der politischen Revolution der Franzosen oder des wirtschaftlichen Freihandels von Adam Smith. Der Erzähler wird so sehr von seinen Vorstellungen mitgerissen, dass das bipolare Modell Córdoba versus Buenos Aires zum gleichfalls bipolaren, aber keineswegs deckungsgleichen oder zumindest kongruenten Gegensatz überleitet zwischen der von Rivadavia verkörperten europäischen Zivilisation und der von Facundo Quiroga und Rosas inkarnierten amerikanischen Barbarei. Mit den „salvajes“, den Wilden sei Buenos Aires über die Pampa, mit Europa über das Meer verbunden. Wohin werde sich diese Stadt neigen?

Die bei Sarmiento so beliebten überlappenden Antagonismen, die sich ständig wechselseitig verschieben und vom Erzähler immer wieder geordnet werden sollen, verweisen auf eine Vorstellung, in welcher die Bipolarität zwar dominiert, sich zugleich aber auf eine tiefer liegende Ebene dazu widersprüchlich verlaufender Antagonismen hin öffnet. Es ist, als wäre Sarmientos Erzähler von der Obsession dieser Antagonismen fasziniert, die Gegensatzpaare aber nur selten im Zaume halten kann, da sich ständig unvorhergesehene Widersprüche einschleichen. Darüber hinaus - das sei hier nicht vergessen - wird Buenos Aires innerhalb eines solchen Raums zur Insel inmitten eines Meeres der Unkultur: Die Identität der Stadt erscheint hier gleichsam als insulare Identität. Buenos Aires ist als Insel eine Welt für sich, eine Insel-Welt, zugleich aber auch eine Inselwelt insofern, als diese Insel weltweit mit anderen Inseln in Verbindung steht - und eben dies ist das Ziel von Domingo Faustino Sarmiento, das er in seiner Zeit als argentinischer Präsident politisch umzusetzen suchte.

Lässt sich Rivadavia mit dem Bild von Buenos Aires noch identifizieren, so geht dies bezüglich amerikanischer Barbarei und spanisch-mittelalterlicher Zivi- 
lisation nicht mehr. So haben wir es zumindest implizit mit einem dreipoligen Modell zu tun, denn der Vergleich der singenden Gauchos mit den mittelalterlichen Troubadouren kann nicht mehr überzeugen: Was vorher noch als Zivilisation (des Mittelalters) dargestellt wurde, kann nun schwerlich als amerikanische Unkultur beschrieben werden. Es ist, als entzöge sich der Text zunehmend den alles dominierenden Binomien auf geschichtsphilosophischer Ebene, trotz aller Versuche des sichtlich darum bemühten Erzählers, eine auf Antinomien aufgebaute Ordnung in jenes Bild zu bringen, das im ersten Teil noch relativ statisch und fixiert gewesen war. Die Dinge geraten in Bewegung, die Textmaschinerie entwickelt ihre eigenen Gesetze: Klare Grenzen verschwimmen, werden an anderer Stelle neu gezogen, überlappen sich in immer neuen Oppositionen, die sich wechselseitig in ihrer Ausschließlichkeit untergraben. Vergessen wir nicht: Sarmientos Text heißt nicht im Untertitel Civilización o Barbarie, sondern Civilización y Barbarie! Es ist ein Bild von Zivilisation und Barbarei, das sich der Leserschaft Facundos bietet.

Ausgehend von dessen Fahne - schwarz, mit Totenschädel, gekreuzten Knochen und dem Motto „Religion oder Tod“ - wird eine Farbsymbolik entwickelt, auf deren oberster Stufe die Farben Blau und Weiß, die Nationalfarben Argentiniens für Frieden und Gerechtigkeit stehen: „azul celeste y blanco.“ Dagegen stehen die Farben der Gegner: „colorado, punzó“, also Rot, eine Farbe, die sich auf Landesfahnen nur in barbarischen Ländern wie Algerien, Tunesien, Türkei, Marokko, Siam, Japan oder in Afrika finde. Den Wilden habe die Farbe Rot stets gefallen, so der Erzähler süffisant: Rot stehe für Terror, Blut und Barbarei. Esteban Echeverría hatte es nicht anders gesehen.

Eine ähnliche Symbolik wird in den Kleidungsstücken entdeckt, mit Hilfe derer sich jede Zivilisation ausdrücke und hinter denen wiederum ein ganzes System von Vorstellungen stecke. Romantik und Freiheit der Ideen führten zu häufigen Kleidungswechseln, tyrannische Barbarei dagegen $\mathrm{zu}$ invariabler Kleidung: eine interessante These, die man zum Teil auch heute noch belegen könnte. Jede Revolution bringe auch einen Kleidungswechsel mit sich; eine Idee, die sich in der Tat gerade am Beispiel der Französischen Revolution belegen ließe, waren bis dahin doch die modischen Grenzen ebenso strikt festgelegt wie die Ständegrenzen des Ancien Régime: Samt und Seide waren dem Adel vorbehalten. Heute - so darf ich als ehemaliger Mitarbeiter eines hochpreisigen Stoffherstellers für die Haute Couture hinzufügen - wird die Sache über Geld geregelt; die Grenzen selbst sind keineswegs verschwunden.

Bemerkenswert ist in diesem Zusammenhang Sarmientos Idee, dass die Mode jeweils nicht von der ganzen Welt bestimmt, sondern von der zivilisiertesten Nation durchgesetzt werde. Wir beginnen zu verstehen, welche Bedeutung der Frack in diesen Vorstellungen spielt; jener Frack, dem Facundo und Rosas 
einen unerbittlichen Kampf angesagt hatten. Juan Manuel de Rosas und seine „Mazorca“ - und auch an dieser Stelle sind wir flugs von Facundo zu Rosas übergewechselt - hätten europäische Kleidung bewusst verfolgt. Und sie hätten ebenso bewusst wie brutal die uns schon aus El matadero bekannte „cinta colorada“ durchgesetzt, verbunden mit jenem Spruch, den wir ebenfalls bei Echeverría kennengelernt hatten und der den Sprachterror des Regimes zum Ausdruck bringt: „Mueran los inmundos salvajes unitarios.“ Lachen dürfe man darüber nicht, schließlich habe die Inquisition auf dieselbe Weise mittels Sprachkontrolle funktioniert: Diese Krankheit, so folgert der Erzähler, tragen wir in unserem Blut! Es war übrigens ein Romanist, Victor Klemperer, der den Sprachterror der deutschen Nationalsozialisten auf die wohl eindrücklichste Weise in seinem Buch LTI über die „Sprache des Dritten Reiches“ analysierte und demaskierte. ${ }^{17}$

Facundo ist ganz nebenbei ein Lehrstück über die Formen und Normen autoritärer und totalitärer Herrschaft. In den narrativen Ablauf, die Lebensgeschichte Facundo Quirogas sind also immer wieder extensive Passagen diskursiver Prägung eingeschaltet, die es dem Erzähler erlauben, die dargestellten Ereignisse zu kommentieren, einzuordnen, auf die damalige Aktualität und den eigenen politischen Kampf zu beziehen, zugleich aber auch ein Geschichtsmodell zu entwerfen, das von der Ebene der kleinen Geschichte her ständig wieder neu angestoßen wird. Die Nation wird zur Narration, ${ }^{18}$ die ihrerseits eine Diskursivität schafft, welche Geschichte selbst als in Bewegung befindliches Objekt vorführt. Ein solches Geschichtsmodell ist in diesem Zusammenhang keineswegs nur das europäischer Zivilisation, wie es der Diskurs bisweilen glauben machen könnte: Gerade auf Ebene der Narration herrscht die sogenannte Barbarei in ihrer kraftstrotzenden und die Gegenwart beherrschenden Präsenz und Gewalt vor. Der Raum der Nation ist mithin nicht nur jener des Diskurses, sondern auch jener andere der Narration: nicht nur Zivilisation und Barbarei, sondern auch Facundo selbst, wie es der Titel schon auf paratextuelle Weise signalisiert.

Die Ereignisse der Geschichte einer Nation, einer Geschichte mit großem $G$, verschwinden dabei keineswegs. Rivadavias Rücktritt, die Machtübernahme der „Federales“, der Mord an Dorrego, der Aufstieg Rosas': All dies ist in die Biographie Quirogas eingeblendet. Sie wird hier zur Historiographie, die Charakterologie zu einer Art Radiographie der Pampa, wie sie später Martínez Estrada in erneuerter Form essayistisch vorlegen sollte. ${ }^{19}$ Die Kämpfe und Schlachten, das

17 Vgl. Klemperer, Victor: LTI. Notizbuch eines Philologen. 15. Auflage. Leipzig: Reclam 1996 18 Vgl. Bhabha, Homi K. (Hg.): Nation and Narration. London - New York: Routledge 1990.

19 Vgl. Martínez Estrada, Ezequiel: Radiografía de la pampa. Edición crítica de Leo Pollmann. Paris: Colección Archivos 1994; vgl. auch Wéinberg, Liliana: Ensayo, simbolismo y campo cultural. 
Abschlachten und Verdrängen des Anderen sind dabei ebenso individualpsychologische wie nationalgeschichtliche Elemente; ganz so, wie sich am Beispiel der „sombra terrible de Facundo“ jenes Rätsel lösen soll, das die argentinische Nation schon im Eingangsteil der Leserschaft gestellt hatte. Die Figur Facundos wächst so über ihre konkrete historische Bedeutung hinaus: Sie wird zu einer mythischen Figur.

Warum aber siegt Facundo? Die Antwort des Erzählers fällt originell aus: Weil seine Gegner, etwa General Lamadrid oder General Lavalle, Argentinier seien. Sind sie nicht Unitarier? Schon, aber sie kämpfen nach Art der Gauchos! Auch für sie kann gelten, was der Erzähler so formuliert: Lupfe man nur ein wenig die Rockschöße des Fracks, mit dem sich der Argentinier verkleide, dann zeige sich darunter stets der „gaucho más o menos civilizado, pero siempre el gaucho“, mithin der ewige Gaucho. Wohlgemerkt: auch bei den Unitariern oder ihren Rechtsnachfolgern - und auch beim Erzähler und Sarmiento selbst.

Die klaren Fronten verschwinden: Facundo kämpft bisweilen ,gauchesk‘, bisweilen unitarisch, die Unitarier oft wie „Federales der Montonera“, welche die kriegerischen Auseinandersetzungen mit wütenden Kavallerieangriffen beginnen. Der Gaucho - so ließe sich sagen - ist überall: auch er eine Obsession, ein Mythos Sarmientos und wohl ebenso der argentinischen Nation. Ein Mythos, der vom Land kam und nun in die Literatur der Städte, in die „ciudad letrada“ eingedrungen ist. Dem Erzähler freilich scheint keine andere Wahl zu bleiben: Er ist dazu verdammt, unendlich viele „horrores“, unendlich viele Schrecken und Gräueltaten zu erzählen. Der Erzähler wird hier selbst ein Stück weit zu jenem „Gaucho cantor“, dessen Figur er neben jene des Rastreador, des Baqueano und des Gaucho malo dem dynamischen zweiten Teil, der eigentlichen Geschichte Facundos vorangestellt hatte. Der Leser werde diese Typen im Verlauf der Geschichte schon selbst identifizieren und man darf gewiss den Cantor mit Sarmientos Erzähler selbst in Beziehung setzen.

Schon zu Lebzeiten Facundos gab es Tendenzen zur Vergöttlichung dieses Caudillo; mehr aber noch bei Rosas, dessen Bild in Kirchen aufgehängt wurde, wie die Proscriptos - allen voran Sarmiento oder auch Mármol - in ihren Schriften nie zu erwähnen vergaßen. Beide Figuren setzt der Erzähler übrigens auch hinsichtlich ihres Verhältnisses zu Terror und Gewalt voneinander ab: Facundo werde leicht wütend, das Blut steige ihm dann in die Augen und er sehe alles „colorado“. Rosas hingegen - so heißt es am Ende des siebten Kapitels im zweiten Teil des Facundo - werde nie wütend, er kalkuliere vielmehr kalt in seinem Arbeitszim- 
mer. ${ }^{20}$ Im Gegensatz zum Terror der französischen Revolution im berüchtigten Jahr 1793 sei Terror bei den Federales freilich längst zu einem Instrument der Macht geworden und nicht mehr bloße Auswirkung geschichtlicher Ereignisse. Doch sehen wir uns einmal eine Szenerie dieses Terrors näher an!

Alles beginnt harmlos: Einen der literarischen Höhepunkte des Bandes stellt zweifellos der Beginn des achten Kapitels im zweiten Teil mit einer lyrischen Beschreibung der Schönheit argentinischer Natur dar. Die Pflanzen-, aber auch die Tierwelt und hier vor allem die Vögel werden in ihrer tropischen Pracht des subtropischen argentinischen Nordens entfaltet. Es ist sehr aufschlussreich, dass sich der Erzähler bezüglich seiner Ausführungen bei einem britischen Reisenden und dessen Reisebericht rückversichert, so dass das europäische Auge, der europäische Blick, auf die exotische amerikanische Tropennatur gerichtet wird. Dieser europäische Blick auf das Argentinische wird als kulturell legitimierte Sichtweise in den Text eingeführt und integriert. Selbstverständlich wird auch ein Alexander von Humboldt nicht von Sarmiento vergessen.

In einem zweiten, klug eingeführten Schritt tritt in dieses Naturbild subtropischer Fauna und Flora, parallel zum Gesang der Vögel, der Gesang des Menschen hinzu. Hierbei kam der Erzähler nicht umhin, den Leser zu fragen, ob dieser nicht denke, es handle sich um ein Plagiat aus Tausenundeiner Nacht - erneut ein Verweis auf die positive Seite des zeitgenössischen literarischen Orientalismus. Freilich verneint er und fügt als krönenden Abschluss die „voluptuosidad“ und Schönheit der Frauen von Tucumán hinzu; Frauen, die - so erklärt der Erzähler sachkundig - im Feuer der Tropensonne reifen. Überflüssig zu sagen, dass dieser Erzähler ein männlicher Argentinier ist und dass der Mythos der schönen Frauen von Tucumán bis heute lebendig blieb.

Sie merken: Der Mythos von der Schönheit dieser Frauen im Norden Argentiniens ist an den der tropisch-exuberanten und wollüstigen Frauen des europäischen Südens gekoppelt, wie er sich im kollektiven männlichen Imaginären bereits seit der griechisch-römischen Antike findet. Im Orientalismus des 19. Jahrhunderts lebte diese Bilderwelt wieder auf, findet sich um die Mitte des Jahrhunderts etwa in französischen Reiseberichten beispielsweise eines Gustave Flaubert und schwappte in veränderter Form auch in die Neue Welt der Amerikas über. Dort wird das eigene Andere unverzüglich orientalisiert.

Doch dann erscheint plötzlich ein krasser Kontrast: Unversehens betritt Facundo Quiroga die Szene - und wie ein Raubtier streckt der Gaucho malo seine Pranken nach frischer Beute aus! Die schönen Tucumanerinnen kommen allesamt zu dem in die Stadt eingefallenen Caudillo, um diesen um das Leben ihrer

20 Sarmiento, Domingo Faustino: Facundo, S. 199. 
Männer, Verlobten oder Geliebten zu bitten. Ich möchte Ihnen diese Szenerie anhand eines gekürzten Auszugs plastisch vor Augen führen:

Tucumán ist ein tropisches Land, wo die Natur ihren großartigsten Glanz zur Schau stellt; es ist das Eden von Amerika, und es gibt auf dem ganzen Erdenrund kein zweites. Stellt Euch die Anden bedeckt von einer grünschwarzen Decke mit einer kolossalen Vegetation vor, die unter der Franse ihres Kleides zwölf Flüsse entspringen lässt, welche in gleichem Abstand zueinander parallel verlaufen, bis sie sich alle nach einem einzigen Ziele ausrichten und vereinigt einen schiffbaren Kanal bilden, welcher keck durch das Herz von Amerika verläuft. [...] Über all dieser Vegetation, welche die phantastische Palette von Kombinationen und Farbenreichtum erschöpfte, flatterten Schwärme von goldenen Schmetterlingen, emailfarbenen Kolibris, Millionen von smaragdfarbenen Papageien, blauen Elstern und orangefarbenen Tukans. Der Lärm dieser kreischenden Vögel betört Euch den ganzen Tag, so als wäre es der Klang eines singenden Liedermachers. [...] Glaubt Ihr vielleicht, dass diese Beschreibung ein Plagiat aus Tausendundeiner Nacht oder aus anderen orientalischen Märchen wäre!? Stellt euch lieber rasch all das vor, was ich nicht von der Wollust und Schönheit der Frauen sage, die unter einem Himmel aus Feuer heranwachsen und schwankend zu ihrem Mittagsschlafe gehen, um sich sanft in den Schatten von Myrte und Lorbeerbaum zu legen und an solchem Orte, trunken von den Essenzen, welche all jene ersticken, die nicht an diese Atmosphäre gewöhnt sind, ihr Schläfchen halten. [...]

Schluchzen entringt sich der ausgesuchten und schüchternen Gesandtschaft; das Lächeln der Hoffnung huscht über einige Gesichter, und alle zarten Verführungen der Frau kommen zur Anwendung, um das mitleidende Ziel zu erreichen, das sie sich gesteckt. Facundo ist lebhaft interessiert, und unter seinem dichten schwarzen Bart ließe sich in seinen Gesichtszügen Selbstgefälligkeit und Zufriedenheit ausmachen. Doch er muss sie eine nach der anderen befragen, von ihren Familien erfahren, vom Haus, in dem sie leben, tausend kleine Dinge, welche ihn zu unterhalten und zufriedenzustellen scheinen, was eine ganze Stunde in Anspruch nimmt und die Erwartungen und Hoffnungen am Leben erhält; am Ende dann sagt er ihnen mit der allergrößten Güte: „Hören Sie nicht diese Gewehrsalven?“21

Sie haben zu Beginn dieser langen Passage das patriotisch stolze Insistieren des Erzählers auf der Schiffbarkeit der Flüsse ebenso wie sein naturräumlich begründetes geopolitisches Denken wiedererkannt, das sich in der Folge zur romantischen Naturdarstellung öffnet, hin zu einer kaskadenartig übereinander sich auftürmenden Sprache sich opulent ausformend. Es sind voluminöse Satzgebilde und Sprachverästelungen, wie sie die neobarocken Sprachformen des 20. Jahrhunderts bei Autoren wie Alejo Carpentier oder Severo Sarduy hervorbringen sollten. Zweifellos haben Sie auch die Ästhetisierung der andinen Welt - noch immer von außen gesehen - erkannt, die auch hier nicht zufällig auf einen britischen Reisebericht zurückverweist. Die Paradiesmetaphorik durfte hier ebenso wenig fehlen wie die Vielfalt schillernder Geschöpfe, die von der Allmacht Gottes

21 Sarmiento, Domingo Faustino: Facundo, S. $204 \mathrm{ff}$. 
in einer paradiesischen Welt zeugen. Denn Eden, das Irdische Paradies, konnte wie schon Christoph Kolumbus wusste - allein in Amerika gesucht werden. Es ist bemerkenswert und auffällig, wie sehr sich Vorstellungen und exuberante Bilder vom Paradies auf Erden durch die Literaturen der Welt ziehen. ${ }^{22}$

In dieses paradiesische Dekor wird die Frau, die Tucumanerin hineingestellt - oder vielleicht sollte man besser sagen: hineingelegt. Denn sie scheint sich innerhalb einer solchen subtropischen Natur mehr der Muße, dem Genusse, der Erotik hinzugeben. Sarmientos Erzähler evoziert, ohne zu benennen: Er spricht von „voluptuosidad“, fordert seine Leser aber auf, an seiner Stelle zu imaginieren, also durch Hypotypose Bilder im Kopf zu erzeugen. Dies ist ein seit der Antike bekanntes rhetorisches Verfahren, das aber gerade bei der erotischen Literatur des 19. und 20. Jahrhunderts gerne angewandt wird.

Die Frau steht in dieser literarischen Darstellung der Natur deutlich näher als der Mann, eine topische Darstellung, die sich quer durch die Literaturen des Abendlandes zieht. Sie wird von ihren Zyklen geprägt, von ihrem Klima umfangen, von der Sonne zum Reifen gebracht und von der Hitze der Tropen zur Siesta im Schatten der Bäume und Haine gezwungen. Diese genderspezifischen Zuordnungen erfolgen ohne jeden Zweifel aus einer männlichen Perspektive innerhalb einer patriarchalisch strukturierten Gesellschaft. Man könnte das Oxymoron wagen, dass die Frauen von Tucumán ein Bild lasziver Unschuld bieten, welches der Erzähler seine (männlichen) Leser hypotypotisch auszugestalten bittet.

Gegen die helle Silhouette dieser engelartigen Geschöpfe - als solche werden sie im weiteren Fortgang der Szenerie apostrophiert: Sie sind dabei freilich keineswegs engelhaft ungeschlechtlich - wird Facundo im Schatten seines schwarzen Bartes inszeniert. Diese diabolische Schwärze kann nur für eine gewisse Zeit durch eine vorgebliche Güte und Freundlichkeit übertüncht werden: Das sympathische Verhalten des Gaucho malo ist kalkuliert und vorgetäuscht. Denn bald schon fällt die Maske; und das Gesicht des Sadisten tritt der Leserschaft plastisch vor Augen in jener nur scheinbar harmlosen, nur scheinbar unschuldigen Frage, welche die Beschreibung der natürlichen und menschlichen Unschuld im idyllischen Tucumán ebenso abrupt wie endgültig beendet. Den schönen Frauen tritt unvermittelt der gewissenlose Mörder ihrer Männer, Verlobten und Geliebten entgegen: Diese nämlich werden auf Befehl Facundo Quirogas zum gleichen Zeitpunkt vollständig nackt auf dem Hauptplatz standrechtlich erschossen - „Hören Sie nicht die Gewehrsalven?“

22 Vgl. hierzu Ette, Ottmar: Konvivenz. Literatur und Leben nach dem Paradies. Berlin: Kulturverlag Kadmos 2012. 
Der schwarze Bart des Facundo mag es noch unterstreichen: Über die paradiesische Welt der tropischen Schönheit ist die Macht des Teufels hereingebrochen. Es ist das Böse in seiner schrecklichsten, verstelltesten, blutdurstigsten Gestalt: Facundo Quiroga, der Gaucho malo, Gegner der Zivilisation! Facundo wird in dieser Passage zugleich zum Gegner der engelsgleichen Wesen und der paradiesischen Tropennatur; er verkörpert das absolut Böse. Sarmientos scharfe Kontraste lassen hieran keinen Zweifel aufkommen.

Es handelt sich dabei um eine Technik, die im lateinamerikanischen Diktatorenroman, der „Novela de dictadores“, oder auch im Roman der „Violencia“ in Kolumbien bis heute immer wieder aufgenommen worden ist. Insofern lassen sich Sarmientos Facundo wie Echeverrías El matadero als einflussreiche Vorläufer dieser langen Tradition lateinamerikanischer Diktatorenromane betrachten. Denn an literarischer Wirkkraft haben diese eindrucksvollen Passagen bis heute nichts verloren.

Mit diesem Bild des diabolischen Facundo möchte ich unsere Beschäftigung mit Domingo Faustino Sarmientos bis heute lebendig gebliebenem Hauptwerk abschließen; vieles gäbe es noch zu sagen über diesen Klassiker argentinischer Literatur der Romantik! Doch will ich die von Sarmiento so meisterhaft verwendete Kontrasttechnik als Anlass dafür nehmen, noch einige zusätzliche Gedanken über die Romantik zwischen zwei Welten anzuschließen und damit unseren literaturtheoretischen Faden wieder aufzunehmen. Dabei gehen wir unverändert davon aus, dass eine germanozentrische oder selbst eine europazentrische Definition von literarischer Romantik lange schon ausgedient hat.

Sicherlich ist auch auf amerikanischer Seite noch immer die ursprüngliche Bedeutung von Romantik zu spüren, welche auf volkstümliche Dichtung setzt und sich von der lateinischen Dichtungslehre - gleichsam der Hochkultur absetzt. Denn das Romanhaft-Phantasievolle grenzt sich auch in den Amerikas ab von einem strengen Neoklassizismus, gegen den immer stärker die populären literarischen Formen einschließlich der Oralität ins Feld geführt werden. In Sarmientos Facundo betrifft dies die durchaus widersprüchliche Aufwertung einer mündlich überlieferten Kultur, einer Erzählwelt der Gauchos und des „Interior“, die vom Autor des Facundo fast widerwillig ihre gleichsam hochkulturelle Adelung erfahren.

Sarmientos Verständnis und mehr noch seine literarische Praxis der Romantik zielen auf eine starke Vermengung unterschiedlichster Stilebenen und kultureller Pole, welche die von ihm bearbeitete Area des Cono Sur prägen. Dabei vermag er es, mit hochkulturellen Traditionen zu spielen und diese in eine komplexere Komposition als intertextuelle Bezugspunkte, nicht länger aber als normative Vorbilder miteinzubeziehen. Seine Literaturtheorie wie auch seine Theorie der Romantik ist schlicht seine literarische Praxis. Dabei spielt eine intertextuelle 
Legitimation mit Hilfe europäischer Zitate und anleihen zweifellos eine wichtige Rolle, bildet aber keineswegs die Grundstruktur eines argentinischen beziehungsweise amerikanischen Verständnisses von Romantik, das sich aus unterschiedlichsten literarischen Bezugstexten und kulturellen Quellen speist sowie durch einen hohen Grad an Heterogenität gekennzeichnet ist.

Außereuropäische Landschaften waren von Beginn der europäischen Frühromantik an - wie wir sahen - recht häufig in den europäischen Literaturen und ihren Hauptwerken zu bewundern, eine Tatsache, welche auch die amerikanischen Schriftsteller zu ihren Darstellungen amerikanischer Natur ihrer jeweiligen Area inspirierte. Sicherlich spielten europäische Reiseberichte eine wichtige vermittelnde Rolle; doch unterschiedlichste Landschaftstypen und Naturbilder entstanden ebenso von den Andenkordilleren wie vom Tiefland der Pampas, von den Randgebieten der Ökumene wie von den subtropischen und tropischen Zentren (auto-)exotisierter Naturszenerien: In der Romantik entfalteten amerikanische Autoren vor ihrer Leserschaft die ganze Fülle der Natur ihres Kontinents. Friedrich Schlegels Diktum „Die romantische Poesie ist eine progressive Universalpoesie“ verdient es, nicht nur germanistisch bezogen, sondern transatlantisch und transareal gedacht und ausbuchstabiert zu werden. Dass romantische Dichtkunst nie vollendet werden kann, zeigt sich ebenso auf der amerikanischen Seite des Atlantik, wenn auch in anderer und origineller transkultureller Form: bei Sarmiento etwa als Hybrid unterschiedlichster Gattungsmuster. Und die Setzung der deutschen Romantik als Durchdringung mit dem Leben wird im entstehenden Lateinamerika hochpolitisch gedacht.

Der scharfe Kontrast, der die gesamte Romantik in Form zahlreicher Gegensatzpaare durchläuft, findet bei Sarmiento eine höchst produktive Aufnahme, insofern er in einer klaren Antithese Zivilisation und Barbarei einander schroff gegenüberstellt. Auch im obigen Zitat hat er die engelhafte Schönheit und paradiesische Unschuld einem diabolischen Kalkül gegenübergestellt, das im Zeichen des Satanischen und Zerstörerischen steht. Doch unterläuft Sarmiento zugleich die antithetischen Strukturen, insofern er angesichts der zivilisierten Modellhaftigkeit europäischer Literatur nicht die Kultur der Gauchos und Rastreadores insgesamt verurteilt, sondern sehr wohl Stärke und Glanz dieser kulturellen Ausdrucksformen in seinem Facundo zur Geltung bringt.

Und auch dies ist romantisches Formdenken: der Wunsch und das Begehren, in einer einzigen Gattung verschiedenste Gattungsformen aufnehmen zu können. Hier spielt die romantische Dialektik von fragmentarischer Unabgeschlossenheit und Totalitätsanspruch in ein Denken hinein, welches im argentinischen und amerikanischen Kontext von einem Sarmiento nicht auf den Roman als Grundform, sondern auf die Gattungstraditionen eines offenen Essays übertragen wurde. Denn Facundo kann aus der Perspektive eines Essays über das grund- 
legende Rätsel Argentiniens sehr wohl Elemente einer Biographie und Autobiographie, einer naturkundlichen Darstellung und eines politischen Traktats, eines literarischen Reiseberichts und vieler weiterer Gattungsformen in sich aufnehmen, ohne dabei eine Einheit der gesamten literarischen Form anzustreben. Die Unabgeschlossenheit all dieser generischen Textbruchstücke ist dabei Programm und zeugt zugleich von einem amerikanischen Stilwillen, welcher die Eigenständigkeit einer amerikanischen Sichtweise hervorhebt. Diese Sprache verkörpert die Sprachgewalt einer amerikanischen Weltschöpfung, der funktionalen Erschließung einer ganzen Hemisphäre: Sie steht mit einem romantischen Weltentwurf, einem amerikanischen Worldmaking im Verbund. ${ }^{23}$

Die in Europa beobachtbare Affinität der Romantik zum Volkstümlichen wie auch zum Märchen und Irrationalen entwickelt sich in den Amerikas zu einer zunehmenden Auseinandersetzung mit den Populärkulturen, wenn auch erst anfänglich mit den Kulturen der indigenen wie der schwarzen Bevölkerungen. Doch die Romantik öffnet just an dieser Stelle ein Fenster auf das, was an der Wende zum 20. Jahrhundert zunehmend in das kollektive Bewusstsein der Lateinamerikaner treten wird: die Kopräsenz unterschiedlicher Kulturen auf einem einzigen Territorium.

Bei Domingo Faustino Sarmiento erscheint dies im Facundo noch als Gleichzeitigkeit des Ungleichzeitigen und damit noch nicht als wirkliche Öffnung gegenüber anderen, nicht-europäischen Kulturen. Es ist vielmehr der Versuch, auf einer Zeitachse verteilte und zueinander kopräsente kulturelle Aggregatzustände zunehmend zusammenzudenken und damit die Hybridität der eigenen kulturellen Situation zur Kenntnis zu nehmen. Dabei stellen das Heraustreten aus einer europäischen Rationalität und die Öffnung für Logiken einer scheinbar anderen Zeit wichtige Veränderungen dar, welche sicherlich etwa von den Reiseberichten eines Alexander von Humboldt thematisiert worden waren, nun aber unter der Feder amerikanischer Schriftstellerinnen und Schriftsteller eine neue Bedeutung erhalten. Sarmientos Facundo erlaubt uns daher, die Romantik nicht nur als ,europäische Erfindung', sondern weiter und zumindest transatlantisch zu denken - eine Sichtweise, die uns mit ihrem Blickwechsel in den kommenden Kapiteln begleiten soll.

23 Vgl. hierzu Nünning, Vera / Nünning, Ansgar / Neumann, Birgit (Hg.): Cultural Ways of Worldmaking. Media and Narratives. Berlin - New York: Walter de Gruyter 2010. 